University of Rhode Island

DigitalCommons@URI

Open Access Master's Theses

1966

\title{
Salt Effect in Vapor-Liquid Equilibrium Methanol-Toluene System
}

Linus Enemmor Aneke

University of Rhode Island

Follow this and additional works at: https://digitalcommons.uri.edu/theses

\section{Recommended Citation}

Aneke, Linus Enemmor, "Salt Effect in Vapor-Liquid Equilibrium Methanol-Toluene System" (1966). Open Access Master's Theses. Paper 1346.

https://digitalcommons.uri.edu/theses/1346

This Thesis is brought to you for free and open access by DigitalCommons@URI. It has been accepted for inclusion in Open Access Master's Theses by an authorized administrator of DigitalCommons@URI. For more information, please contact digitalcommons-group@uri.edu. 
SALT EFFECT IN VAPOR-LIQUID EQUILIBRIUM

METHANOL-TOLUENE SYSTEM

BY

LINUS ENEMMOR ANEKE

A THESIS SUBMITTED IN PARTIAL FULFILLMENT DF THE REQUIREMENTS FOR THE DEGREE OF

MASTER OF SLIENCE

IN

CHEMICAL ENG INEERING

UNIVERSITY OF RHODE ISLAND

1966 


\section{MASTER OF SCIENCE THESIS \\ OF}

LINUS ENEMMOR ANEKE

Approved;

Thesis Committee
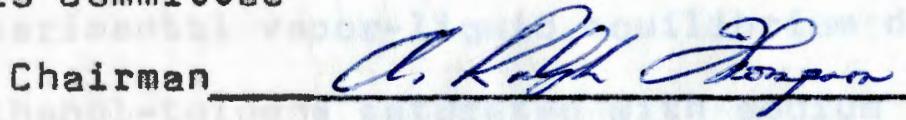

Cuncent C Rose

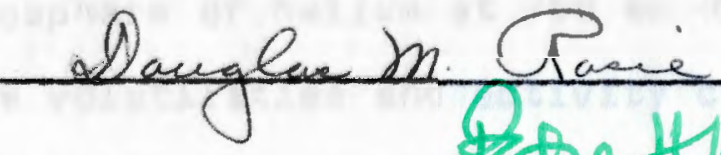

Dean of the Graduate School

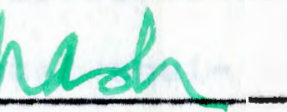

UNIVERSITY OF RHODE ISLAND

1966 


\section{ABSTRACT}

Vapor-1iquid equilibrium data for the system methanol-toluene saturated with sodium bromide were determined at $760 \mathrm{~mm} \mathrm{Hg}$ in an improved othmer equilibrium still. The importance of salt-affect and the role of salt as a third component are discussed.

Analytical data for methanol-toluene solutions saturated with sodium bromide at $25^{\circ} \mathrm{C}$, are roported in the form of a refractive index-composition curve. Compositions were expressed on a salt-free basis.

Experimental vapor-liquid equilibrium data for the system methanol-toluene saturated with sodium bromide are reported over the entire composition range. The data were obtained in an atmosphere of helium at $760 \mathrm{~mm} \mathrm{Hg}$ total pressure. Relative volatilities and activity coefficients were calculated and reported from the experimental equilibrium data. The significance of the relative volatilities and the activity coefficients was discussed. The data obtained by Burke and co-workers (8) for the binary system methanol-toluene were compared with those obtained in this study.

The experimental data were tested by the method of Rodlich and Kister (56) and found to be thermodynamically consistent. A summary of the work done in salt-effect in vapor-liquid equilibrium is presented and suggestions for future work are made. 


\section{ACKNOWLEDGMENT}

The author wishes to express his appreciation to Dr. A. Ralph Thompson, Professor and Chairman of the Department of Chemical Engineering, under whose direction this research was conducted, for his help at every stage of this investigation: Many thanks are also extended to the other members of his committee, Dr. Douglas m. Rosie, Associate Professor of Chemistry, and Dr. Vincent C. Rose, Assistant Professor of Chemical Engineering, for their helpful advice.

The author also wishes to acknowledgo the helpful suggestions volunteered by Mr. Frederick stern and Associate Professor of Chemical Engineering, Dr. Ferdinand Votta, Jr.

Finally the author would like to express his gratitude to the African-American Institute and the University of Rhode Island for their financial support under their African-Graduate Fellowship Program. 
I. INTRODUCTION AND THEORY .......... 1

A. The Problem ............. I

B. Systom Investigated ......... 3

C. Importance of Salt-Effect ...... 5

D. The Role of a Salt as a Third Component .......... 9

E. Corralating Salt-Effect in Vapor-Liquid Equilibrium ........ 12

II. EXPERIMENTAL . . . . . . . 17

A. Chemicals Used ............ 17

日. Apparatus . . . . . . . . . 21

C. Analytical Technique . . . . . . 24

D. Experimental Procedure ...... 30

1. Charging the still ...... 30

2. Pressure Control ...... 31

3. Temperature measurements ... 31

4. Sampling Techniqus ...... 31

5. Refractive-Index Measurements. 32

III. EXPERIMENTAL RESULTS . . . . . . 33

A. Experimental Vapor-Liquid Equilibrium Data . . . . . . . . 33

B. Boiling Point-Composition Data . . . 36

C. Rofractive Index-Composition Data at $25^{\circ} \mathrm{C}$............. 39

IV. CAlculated Results .......... 40 A. Mole fraction ......... 40 
CHAPTER

PAGE

8. Relative Volatility....... 4 41

C. Activity Coofficients ...... . 45

V. TEST FOR THERMOOYNAMIC CONSISTENCY ..... 51

VI. DISCUSSION AND CONCLUSIONS . . . . . . 55

VII. SUGgESTIONS FOR FUTURE WORK ....... 58

VIII. SUMMARY . . . . . . . . . 59

IX. APPENDIX ..................... 60

X. NOMEnClature ................ 71

BIBLIOGRAPHY ............... 72 


\section{LIST OF TABLES}

TABLE

PAGE

I. Refractive Index-Composition Data at $25^{\circ} \mathrm{C}$, for

Methanol-Tolueno Solutions Saturated with

Sodium Bromide . . . . . . . . . . 28

II. Experimental Vapor-Liquid Equilibrium Data of

Methanol-Toluene-Sodium Bromide System

(under Melium) . . . . . . . . . 34

III. Boiling Points at Atmospheric Pressure of

Methanol-Toluene Solutions Saturated with

Sodium Bromida . . . . . . . . . 37

IV. Ralative Volatilities of Methanol-Toluene

Saturated with Sodium Bromide ...... 43

V. Activity Coefficient-Composition Data for the

methanol-Toluene system ........ 48

VI. Values Calculated for Thermodynamic Consistency

Test . . . . . . . . . 53

VII. Experimental Equilibrium Data for Methanol-

Toluene at $760 \mathrm{~mm} \mathrm{Hg} \mathrm{(Burke} \mathrm{t} \mathrm{al.)} \mathrm{....} 62$

VIII. Refractive Indices of Mixtures of Methanol-

Toluene at $250^{\circ} \mathrm{C}$.......... 63

IX. Activity Coefficient-Composition Data for

Methanol-Toluene (Burk et al.) ..... 64

X. Summary of Vapor-Liquid Equilibrium Data with

Salt as a Third Component . . . . . . 65

XI. Solubilities of Various Salts in Alcohols at

Room Temperature in Gms/100 Gm Solvent... 68 
TABLE

PAGE

XII. Relative Volatilities of Mothanol-Toluene mixtures (Burke t al.) ........ 69

XIII. Vapor Pressures of Methanol and of Tolusne at

$$
\text { Various Temperatures ....... } 70
$$




\section{LIST OF FIGURES}

FIGURE

PAGE

1. Equilibrium Still--Improved Othmer Type . . 20

2. Refractive Indices of Mixtures of Methanol and

Toluene at $25^{\circ} \mathrm{C} . . . . . . .27$

3. Vapor-Liquid Equilibrium Curve for Mothanol-

Toluene System . . . . . . . 35

4. Boiling Points of Methanol-Toluene Saturated

with Sodium Bromide... . . . . . 38

5. Relative Volatility of Methanol-Toluene

mixtures ............ 44

6. Vapor Pressures of Methanol and of Toluene . . 47

7. Activity Coefficient-Composition Curves for

the Methanol-Toluene System ....... 49

8. Plot for Thermodynamic Consistency Test . . . 54 


\section{INTRODUCTION AND THEORY}

\section{A. The Problem}

The objective of this study was to investigate the effect of a dissolved salt on the vapor-liquid equilibrium of a binary system comprised of liquid components. Salteffect in vapor-1iquid equilibrium depands on the solubility characteristics of the salt and on the solvent properties of the liquid. Extensive studies have been made over the years of the ffect of different salts on the vapor-liquidequilibrium of several binary organic mixtures. The interaction of a binary liquid mixture and a salt can fall into one of three categories:

1. The salt may be soluble in the high-boiling component and insoluble in the low-boiling one.

2. The salt may be soluble in the low-boiler and insoluble in the high-boiler.

3. The salt may be appreciably soluble in both components.

The first type is illustrated by the invostigations of Rieder and Thompson (57) who studied the system thanolwater saturated with potassium nitrate. The work of Tursi and Thompson (70), who used the system ethanol-water saturated with sodium sulfate, potassium sulfate and sodium nitrate, also comes under this type. From their findings these investigators came to two conclusions: 
1. The addition of a salt which is relatively soluble only in the high-boiling component will cause a greater ease of separation between the components of a binary mixture.

2. The ease of separation increases as the solubility of the salt in the high-boiling component increases. The second type is illustrated by the work of Ciesla (15) on the system thanol-water-dimethylglyoxime. Dimethylglyoxime is relatively soluble in thanol and insoluble in water. The rolative volatility curve for this system shows a decrease in the volatility of thanol as a result of the addition of the salt.

The third case is exemplified by the work of Chen (11), who invastigated the system glycerol-water-sodium chloride. Sodium chloride is soluble in glycarol as well as water.

In the systems mentioned above, the binary liquid mixtures were saturated with salt. A summary of the work to date on vapor-liquid quilibrium with salt as a third component is given in Table $X$ in the Appendix.

The present investigation was carried out on a system in which the salt was relatively soluble only in the low-boiling liquid component. 


\section{B. System Investigated}

The system studied was methanol-toluene, saturated with sodium bromide. Mixtures of methyl alcohol and toluene are used in chemical processing. These solvents are frequently recovered or repurified by distillation. Vapor-liquid equilibrium data have been determined for this binary system by Burke and co-workers ( 8 ) and by Benedict and co-workers (2). The work of these investigators showed that a minimum-boiling azeotrope is formed at approximately 0.885 mole fraction methanol and a temperature of $63.6^{\circ} \mathrm{C}$.

The purpose of the present work was to see what effect, if any, a salt such as a sodium halide would have on the vapor-liquid equilibrium of the system methanoltoluene. Sodium halides are vary soluble in methyl alcohol but practically insolube in toluene. This work had the further purpose of trying to establish whether the salt would "break" or shift the azootrope and make possible a more complete separation of the binary mixture by distillation.

Many investigations into salt-effect in vapor-liquid equilibrium have established that, for any appreciable effect on the vapor-liquid equilibrium to be observed, the salt must be reasonably soluble in the system. In other words, the influence exerted on the system increases as the solubility of the salt in the system increases. Sodium iodide was initially used in this study because it was very 
soluble in methanol. Other salts such as calcium nitrate, cupric chloride and sodium bromide, which are soluble in methanol, were also available.

The use of sodium iodide was discontinued because it is one of those salts which are so soluble in methanol that the binary mixture of methanol and toluene separated into two liquid phases. Sodium iodide, calcium nitrate and cupric chloride all produced this effect at room temperature while, with sodium iodide, the two liquid phases persisted even at elevated temperatures. In this study, a twomphase liquid system was obviously undesirable because the improved othmer still had no provision for sampling a twophase liquid system either in the still-pot or in the condensate trap. Thus, although it was recognized that a two-phase liquid system would have made a very interesting study, it was not practical. The problem was eventually solved by substituting sodium bromide for sodium iodide. The former is much less soluble in methanol than the latter and therefore does not break the binary liquid mixture into two phases. The solubilities of saveral salts in methanol are presented in Table XI in the Appendix for comparison. 
C. Importance of Salt-Effect

salt-effect in vapor-liquid equilibrium is of definite industrial importance. This may be the reason for the research forts already undertaken on the effect of various salts on the vapor-liquid equilibria of several binary mixtures and of ways of correlating and estimating salt-effect in vapor-liquid equilibrium. Extractive and azeotropic distillation are already widely used in industry in the separation of mixtures whose components boil so close together that they cannot be economically separated by fractional distillation. These special techniques have also been successfully used in separating mixtures which form azeotropes. In a similar manner, the addition of a salt to a binary mixture produces changes in relative volatility of the systems which can be adapted to separate the mixture into its components. Since the addition of a salt soluble in the high-boiling component increases the rolative volatility of the more volatile component, it has been suggested (15) that an industrial application would be to add a salt directly to the still-pot of a fractionating column to increase the separation. The salt-affect, however, is not limited to increasing relative volatility. This was noted in the work of Garwin and Hutchison (22), in which acetic acid was separated from water. In this case a condition of revarsed relative volatility was observed because of the presence of calcium chloride. In the fractional distillation of a binary mixture of water and acetic acid, water is recovered in the overhead and 
acetic acid in the bottoms. By saturating the mixture with calcium chloride, acetic acid is recovered in the overhead and water in the bottoms. An advantage of this reversed relative volatility is that acetic acid, which now appears at the top of the column, may be recovered from dilute solutions of acetic acid in water with a small amount of heat and therefore reduced costs.

Several investigators $(23,24,68,69)$, have proposed a method for the recovery of inorganic salts from aqueous solutions by the addition of a liquid organic solvent to crystallize out the salt. For such a process to be commercially feasible, the solvent must be cheaply racovered. since this is usually done by distillation, the effect of the salt on the vapor-liquid equilibrium of the system would have to be known.

Many organic syntheses involve an alkali or acid hydrolysis of an intermediate compound resulting in an organic-water-salt mixture from which the valuable organic product must be separated. In many such cases, distillation affords the most economical means of separating the components. The presence of the salt will affect the vapor-liquid equilibrium relationship of the system. Its effect must therefore be determined. The large scale manufacture of phenol involves an alkaline hydrolysis of chlorobenzene. In this process, known as the Dow process (45), chlorobenzene is allowed to react with aqueous sodium hydroxide at a temperature of about $360^{\circ} \mathrm{C}$, and a pressure of 4500 p.s.i. 


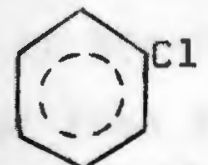

chlorobenzene

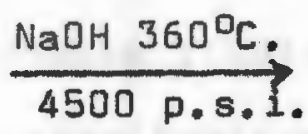

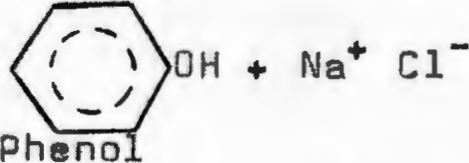

The product is sodium phenoxide which is neutralizad by hydrochloric acid to yield a phenol-water-salt solution. It is very difficult to isolate phenol in this synthesis. Bogart and Brunjes (4) have shown that recovery becomes commercially feasible, by distillation, in the presence of a salt. The salt performs a function comparable to a solvent in extractive distillation.

Another application of the salt-effect in vaporliquid equilibrium is in attempting to "break" or shift the azeotrope of a binary mixture. Mariller and Coutant (41) successfully used this technique to produce anhydrous ethanol from an ethanol-water mixture by the addition of mercuric chloride as a third component. Kyrides and coworkers (36) used the alkali salts of high-boiling alcohols, glycols, and glycerol for the dehydration of the lower-boiling alcohols which are difficult to dehydrate by ordinary means, although it was not possible to obtain absolute alcohol by this method. Thompson and molstad (68) proposed a method for producing anhydrous isopropanol. They found that if an isopropanol-water mixture is 
saturated with ammonium nitrate above $41^{\circ} \mathrm{C} .$, the upper layer of the two-phase liquid formed will be richer in alcohol than the azotropic mixture. This upper layer may then be decanted at any temperature above $41^{\circ} \mathrm{C}$. and subjected to fractional distillation in a suitable column to produce anhydrous isopropanol. 
D. The Role of a Salt as a Third Component

The usual ternary liquid system relationships do not apply to binary liquid mixtures saturated with salts, because of the non-volatile nature of the salts. Furthermore, the physical laws of solutions are inapplicable to solutions of electrolytes, especially concentrated solutions of electrolytes, since many of these physical laws are based on the assumption of ideal behavior and are generally applicable only to dilute solutions (17). The role of a salt as a third component in a binary liquid mixture can be correlated in terms of the four colligative properties of solutions: vapor-pressure reduction, boiling-point elevation, freezing-point dopression, and osmotic pressure, which are closely inter-related. The most obvious relation would be between the lowering of the solvent vapor-pressure upon addition of a solute and a corresponding reduction in the volatility of the solvent. Thus, a salt that is soluble in the less volatile component of a binary system and insoluble in the more volatile component would effectively increase the relative volatility of the more volatile component and make separation sasior. Conversely, if the salt is soluble in the more volatile component, separation would be more difficult.

Another factor which must be considered in a quantitative study of salt-affect is the extent of dissociation or association of the solutes in solution. If there is dissociation, the vapor-pressure lowering, boiling-point - levation, freezing-point depression, and osmotic pressure 
will be increased over the values expected for a non-dissociating solute. For an associating solute, these quantitios will be decreased (17). In order to avoid complications, most of the quantitative study on solutions nave been restricted to dilute solutions of solutes which do not dissociate or assoclate in solution (17). Another problem that may arise is the possibility of intermolecular reaction or ionic-molecular attraction between the salt ions and the molecules of one or both of the solvents. It seemed reasonable to postulate that inter-ionic forces, ion-molecule forces, polarity of the solvents, dielectric constants of the solvents, and perhaps many other phenomena play some part in datermining the ffect of any salt on any binary system. However, Fogg (20) has stated that the concentration of the salt would be the primary factor in determining the magnitude of the salt-effect, whereas the relative solubilities of the salt in the two liquid components would control the direction of the change of relative volatility.

In cases where normal distillation methods are impractical, a third component is introduced into a distillation charge to improve the separation. This difficulty of separation may be a result of azeotrope formation or of very low relative volatility over a wide concentration range. Therefore by adding a third componant which will reduce the partial vapor pressure of the higher-boiling componant without affecting the other, the relative volatility of the mixture will be enhanced and soparation by 
distillation will be easier. Most industrial applications of this technique in extractive and azeotropic distillation have employed a liquid as a third component. Walker and his colleagues (74) suggested a modification of this method by the addition of a material which is very solubl in one but not in the other component. Such a material would obviously lower the vapor pressure of the first component but not the sacond. The work of Rieder and Thompson (57), and Tursi and Thompson (70), and others, have verified that the relative volatility of a binary mixture is increased by the addition of a salt soluble in the high-boiling component and insoluble in the low-boiling.

The non-ideality of a given mixture is indicated by the activity cofficients. Therefore the effect of the third component can be observed by noting the difference between the activity coefficients of this mixture and that of the corrasponding binary mixture. Studies by several investigators (57) confirm that the addition of a salt to a binary liquid mixture increases the non-ideality of the system. However, there are other factors contributing to the non-ideality of a system besides the selt-effect. These include:

1. Differences in "internal pressure" or molecular attraction force which favor positive deviations.

2. Compound-formation botween two components or a marked difference in size, giving negative deviations. 
E. Correlating Salt-Effact in Vapor-Liquid Equilibrium

Several investigators have attempted to develop correlations for the prediction of salt effect in binary vapor-liquid equilibrium. Notable among these are Ramalho and Edgett (54), Tursi and Thompson (70), Fogg (20), Lu (37), and Johnson and Furter $(31,32)$.

Lu (37) proposed a method which uses, as primary information, the vapor-pressure lowering of the pure components resulting from addition of salt, and vapor-liquid equilibrium data under salt-free conditions. The proposed empirical method is limitad to the following conditions:

1. The salt does not have any chemical effect on the components, such as the formation of hydrate or alcoholate with the liquid components.

2. The salt-free binary system does not deviate much from ideality.

3. The salt solution is saturated. In dilute salt solutions, the vapor-pressure lowering of the pure solvents is related to the concentration through Raoult's Law.

$$
x_{s}=\frac{p^{0}-p}{p^{0}}
$$

where $x_{s}$ is mole fraction of the solute; $p^{0}$ is the vapor pressure of the pure solvent; and $p$ is the vapor pressure of the solution at the same temperature. For binary vaporliquid equilibrium calculations, under salt-free conditions, and assuming that the vapor phase is an ideal mixture, the total pressure is given by

$$
\pi=x_{1} \gamma_{1} p_{1}^{0}+x_{2} \gamma_{2} p_{2}^{0}
$$


where $\gamma$ refers to activity coefficient and subscripts 1 and 2 refer to components 1 and 2 respectively. For saturated solutions, Equation I often does not apply. Hence Lu defined a pseudo mole fraction of the solute using Equation 1. When salt is added, the liquid mole fraction terms in Equation 2 are modified as follows:

$$
\begin{aligned}
& x_{1}^{\prime}=\frac{x_{1}}{x_{1}\left(\frac{p_{1}{ }^{0}}{p_{1}}\right)+x_{2}\left(\frac{p_{2}{ }^{0}}{p_{2}}\right)} \\
& x_{2}^{\prime}=\frac{x_{2}}{x_{1}\left(\frac{p_{1}^{0}}{\left(p_{1}\right.}\right)+x_{2}\left(\frac{p_{2}^{0}}{\left(p_{2}\right.}\right)}
\end{aligned}
$$

where $p_{1}$ and $p_{2}$ are vapor pressures of the solutions, salt plus pure liquid 1 and salt plus pure liquid 2, respectively, at the boiling point; $\mathrm{p}_{1}{ }^{0}$ and $\mathrm{p}_{2}{ }^{0}$ are the vapor pressures of the pure components 1 and 2, respectively, at the same temperature. According to Equation $1, \frac{p^{0}}{p}=\frac{1}{1-x_{s}}$. Using I mole of salt free solution, the ratio $\frac{p^{0}}{p}$ gives the total number of moles of salt solution available (number of moles of salt and I mole of salt-free liquid). In Equation 3 , the term $\frac{P_{1}{ }^{D}}{P_{2}{ }^{0}}$, means the number of moles of salt solutions per mole of salt-free liquid component 1 , and the torm $x_{1}\left(\frac{p_{1}^{0}}{p_{1}}\right)$ represents the number of moles of salt solution contributed from liquid component l. Similarly, $P_{2}$ 
salt-free liquid componant 2 while the term $x_{2} \frac{\left(\mathrm{P}_{2}{ }^{\mathrm{D}}\right)}{\left(\mathrm{P}_{2}\right)}$ represents the number of moles of salt solution contributed from liquid component 2. In both cases, pseudo mole fraction of the salt is employed. Thus the quantities $x_{1}^{\prime}$ and $x_{2}^{\prime}$ in Equation 3 may be considered as the effective mole fractions of the liquid components. The quantities $\gamma_{1}$ and $\gamma_{2}$ may be taken from the salt-free vapor-liquid data at the corresponding $x_{1}$ and $x_{2}$. Thus the boiling point corresponding to the given total pressure $\pi$ can be determined by the equation

$$
\pi=x_{1}^{\prime} \gamma_{1} p_{1}^{0}+x_{2}^{\prime} \gamma_{2} p_{2}^{0}
$$

The auilibrium vapor compositions are evaluated by

$$
\begin{aligned}
& y_{1}=\frac{x_{1}^{\prime} \gamma_{1} p_{1}^{0}}{\pi} \\
& y_{2}=\frac{y_{2}^{\prime} \gamma_{2} p_{2}^{0}}{\pi}
\end{aligned}
$$

The correlation proposed by Ramalho and Edgatt (54) is interesting because it was designed to apply only to non-saturated solutions. In nearly all the correlations proposed by previous investigations, saturated salt solutions were employed so that a more pronounced effect would be observed. Ramalho and Edgett, however, decided to avoid saturated solutions, but made the salt cancentration in solution a constant parameter for each system studied. They proposed a correlation which would permit prediction of the salt effect from a minimum of experimental data. The authors also presented a theoretical justification for the 
proposed correlation, based upon consideration of the change of chemical potentials of the two volatile components due to salt addition. The correlation consisted of the use of reference-system charts with the following coordinates. ordinato: Relative volatilities $\left(\alpha_{s}\right)$ for the system 1-2-salt, where 1 and 2 are the 1 iquid components. Abscissa: Values of the ralative volatilities $(\alpha)$ for the reference system 1-2.

The ordinates are plotted versus the abscissa at corresponding equal values of the liquid composition $x$. Several straight lines are obtained corresponding to the several different concentrations of dissolved salt. The straight line relationship fails only after saturation is rached. When this happens, the concentration of dissolved salt is no longer constant since salt-precipitation occurs. This means that there is a variation in the concentration of dissolved salt over the binary liquid composition range. This is due to the fact that the solubility of the salt is usually not the same in the two liquid components at all compositions, even though the liquid mixture may be saturated at the different binary compositions.

Fogg (20) proposed an empirical correlation which relates the fractional change in the activity coefficients of both components, caused by addition of a salt, to the solubility of the salt in the pure components. From this correlation, he believed that the effect of any salt on a binary system can be predicted under the following conditions: 
1. Experimental data are available for the effect of three or four representative salts on the systom.

2. The salts do not react with the liquid components.

3. The salts exhibit similar ionic properties. 
II. EXPERIMENTAL

\section{A. Chemicals Used}

Toluene. The toluene used in this work was of analytical reagent grade, purchased from the Mallinckrodt Chemical Works. The boiling point of the chemical was quoted as $110.6^{\circ} \mathrm{C}$. which is the literature value of the normal boiling point of toluene. The maximum impurities were 1 isted as $0.03 \%$. The boiling point of the toluene was experimentally determined in the apparatus of this investigation to be $110.6^{\circ} \mathrm{C}$. As a further check of the purity of this reagent, a sample was analyzed on a gas chromatograph. No impurities were detected at the highest sensitivity of the instrument. As a final check for purity, the refractive index of the toluene was determined and found to be $n_{D}^{25}=1.49420$. This value is in good agreement with the literature value $n^{25}=1.49428$ reported by Burke and comorkers (8). The toluene was therefore used without further purification. Methanol. The methanol, also purchased from the Mellinckrodt Chemical Works, was of analytical reagent grade. It was specified to be anhydrous and acetone-frea, with a boiling point of $64.6^{\circ} \mathrm{C}$. The minimum assay was quoted as $99.5 \%$ methanol by volume and the water content was guaranteed to be no more than $0.10 \%$. Refractive index measurements and gas chromatogrephic analysis showed that further purification was necessary. In the gas 
chromatographic analysis of the methanol, a small peak, other than that for methanol, was observed. A few drops of water were deliberately added to the methanol sample and another analysis was carried out. Peaks were observed at the same places as before except that the impurity peak was considerably increased. This simple test indicated that the impurity was water. The methanol was therefore distilled over calcium oxide and the middle cut was retained. The boiling point was found to be $64.7^{\circ} \mathrm{C}$. which is the value given in the literature for pure methanol (30). The refractive index $\left(n_{D}^{25}\right)$ of the methanol was found to be 1.32690 at $25^{\circ} \mathrm{C}$. This value is very close to that determined by Burke and co-workers $(\theta), n_{D}^{25}=1.32691$. Chromatographic analysis of the distilled methanol showed only one peak, obviously that for methanol. This indicated that the methanol had been successfully purified.

Sodium Bromide. The sodium bromide used in this study was a product of the Ceneral Chemical Division of the Allied Chemical Company. The salt was of reagent grade and in granular form. It was used as received without further purification. 


\section{B. Apparatus}

The vapor-liquid quilibrium still employed was an 800-ml. improved Othmer still shown in Figure 1. This type of still has been widely used with great success by several investigators $(11,15,54,57,70)$. Moreover, the improved othmer type was rated very high by fogg (20) in his comparison of equilibrium stills. However, it was recognized that a recycling type of equilibrium still like this ons, also known as a continuous distillation quilibrium still, has advantages as well as disadvantages. The main advantages are that it is simple and that the unit can be placed in operation and allowed to come to a steady state without any great amount of attention (60). The disadvantages which may lead to serious errors are (60):

1. Partial condensation of the vapors, thereby increasing the concentration of the mor valatile componont in the vapor.

2. Entrainment of liquids in the vapor leaving the still-pot, thus inereasing the concentration of the less volatile component in the vapor.

3. Inadequate or slow mixing of the returning condensate with the liquid in the still-pot causing the condensate, which is of a different composition from the liquid in the still and, in general, of a lower boiling point to flash as soon as it meats the hot liquid. The vapor obtained in this case is not an equilibrium vapor.

4. This mothod assumes that the vapor obtained by boiling a liquid is in equilibrium with the liquid. There 


\section{FIGURE I}

IMPROVED OTHMER STILL 


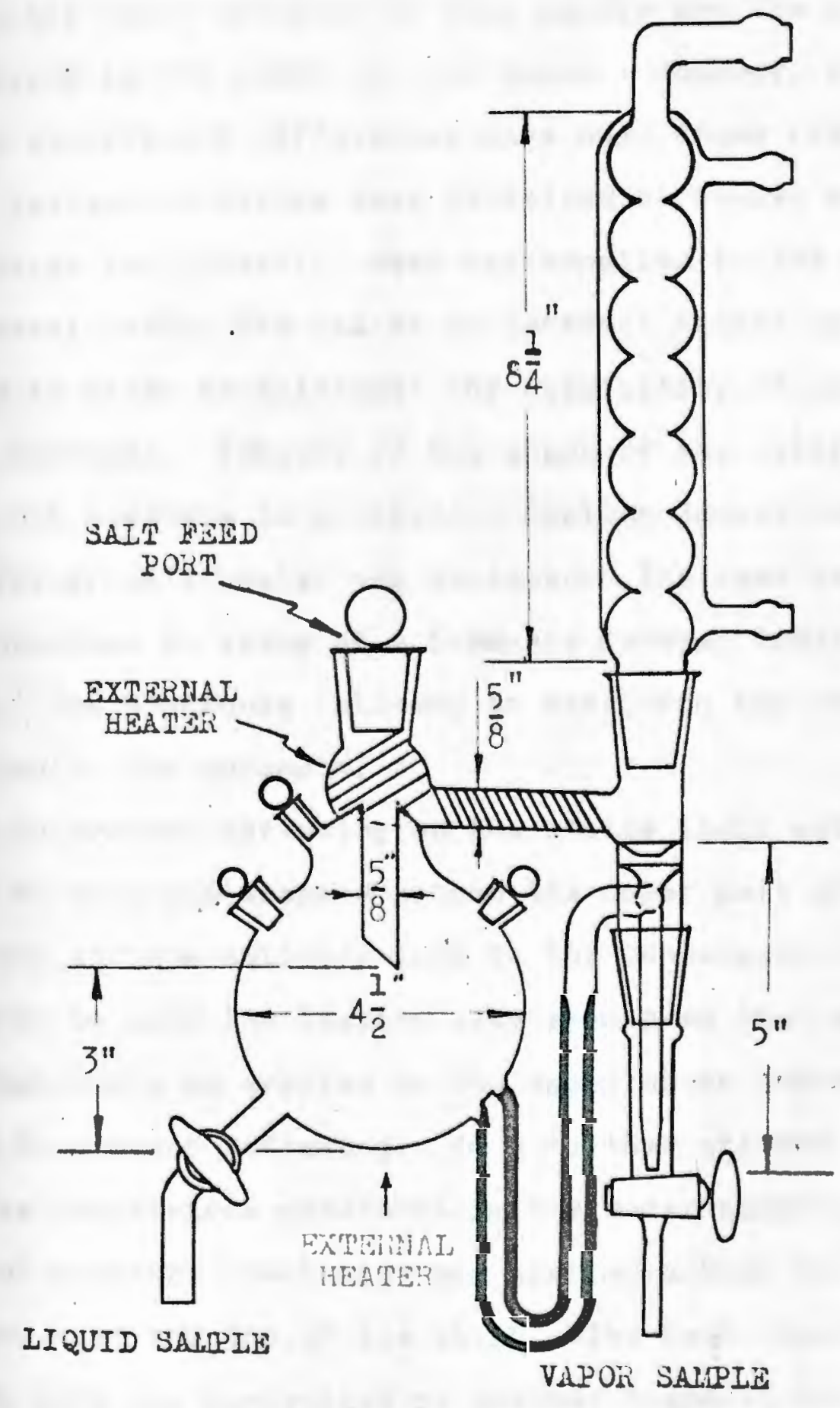


has been no adequate proof of this assumption. Some theoretical considerations would tend to indicate that equilibrium should not be obtained (60). Avallable experimental data indicate that the difference in composition between the vapor obtained in this manner and the true equilibrium is not great in most cases. However, in a fow systems significant differences have been found (60). Systematic orrors were minimized by proper equipment design and control. Heat was supplied to the still by an external heater. The use of an internal heater was avoided in order to eliminate the possibility of oxidation of the methanol. Because of the shape of the still-pot, it was not possible to purchase a heating jacket that would fit. Therefore a heater was designed. The heat input was controlled by means of a 5-ampere General Radio Company Variac. The procedure followed in designing the heater is presented in the Appendix.

To prevent refluxing on the inside still wall, a length of wire was wrapped around the upper part of the still-pot and the delivery tube to the condenser. Care was taken to wind the heating wire evenly so that an even superheat could be applied to the vapor above the boiling liquid to prevent refluxing. In a further attempt to minimize temperature gradients in the superheated vapor, a layer of asbestos insulation was applied around the heating wire and over the top of the still. The heat input to this heating wire was controlled by another 5-ampere Variac made by the General Radio Company. The still was enclosed in a 
large wooden box, which was open at the top and was -quipped with glass doors at the front so that the still could be observed from autside. With these precautions the effects of air currents were minimized and the still was assumed to operate under adiabatic conditions.

A Cartesian Manostat, Model \#8, made by Greiner Scientific Corporation, was used to maintain the system at a constant pressure of $760 \mathrm{~mm} \mathrm{Hg}$. A tank of helium was used to supply pressure to the system while vacuum was obtained with a water aspirator. With this type of manostat there was no need for a surge tank because the instrument responded immediately to any slight pressure rise in the system. All experimental data were taken at $760 \pm 2.0 \mathrm{~mm}$ of mercury. The manometer was made by the Meriam Company of Cleveland, Dhio. Mercury was the manometric fluid.

Vapor tomperatures in the still were measured with a mercury-in-glass thermometer whose scale is in $0.2^{\circ} \mathrm{C}$. divisions. Because of the superheat required to prevent rofluxing, accurate measurement of the boiling temperature in the still was not possible. Rather, boiling point data were obtained in a $2000 \mathrm{ml}$. three-necked flask, which was køpt approximately one-half full with saturated solution. A condenser was inserted into the center neck so that boiling could be done under total reflux. The top of the condenser was connected to the pressure controller described above so that the normal boiling points of the mixtures could be obtained. In one side neck a calibrated 
thermometer was immersed in the liquid so that the boiling temperature of the latter could be determined. In the other side neck another calibrated thermometer was located approximately one inch above the surface of the liquid in order to give the temperature of the vapor assumed to be in equilibrium with the boiling liquid. The ffect of radiation on the thermometers was assumed negligible. Corrections were made for the emergent stem of the thermometer.

Ten ml. Weld-type, capped specific gravity bottles were used to weigh the liquid mixtures used in preparing the refractive index-composition calibration curve for the system methanol-tolume saturated with sodium bromide. special 75-ml. narrow-necked bottles wore used for all liquid samples for the refractive index analysis. 
C. Analytical Technique

Refractive index-composition data have been reported for the system methanol-toluene by Burke and co-workers (8). Three main reasons indicated the use of refractive index measurements as the analytical technique: high accuracy; relatively short times required to analyze each sample; and the need of only small samples for each analysis. In addition to the above reasons, it was intended to use the data of Burke and co-workers to plot a calibration curve of refractive index versus composition for the system methanoltoluene containing no salt. Because the data of Burke and co-workers were determined at $25^{\circ} \mathrm{C}$., all refractive index measurements made in the present study were at $25^{\circ} \mathrm{C}$.

For the refrective index measurements, a Bausch and Lomb precision refractometer was employed. Using this instrument, it was possible to reproduce refractive index measurements with a precisian of \pm 0.00005 , but the values were reported to only four decimal places. The temperature of the prism was maintained at $25 \pm 0.05^{\circ} \mathrm{C}$. by a precision constant temperature bath. Burke and co-workers (8) claimed that the refractometer yielded analyses with an estimated maximum error of \pm 0.03 mole $\%$ absolute. Their claim seems to be too optimistic. The data from the present study, like those of Burke et $a 1$, are reported to the nearest 0.1 mole \%. The General Electric Sodiun Lab-Arc, which is installed as a permanent part of the precision refractometers, was used as a light source in the determination of the basic index values. A type NB Colora UItra-Thermostat 
constant temperature bath was used. It has a built-in pump which circulates the bath water through the rafractometer prisms. Typically, only a fow trials of cooling water flow rate were required. Once the right flow rate was established and steady operation was obtained, the temperature was constant at $25 \pm 0.05^{\circ} \mathrm{C}$.

In order to obtain reproducible results, it was necessary to transfer samples to the refractometer as quickly as possible. This was accomplished by the use of medicine droppers. The number of drops of sample used tended to make a slight difference in the sharpness of the dividing line which consequently affected the results obtained. In order to obtain reprodubible results, two, or at the most three, drops were used each time. As a final precaution any drops suspended at the tip of the dropper were absorbed on blotting paper. This was necessary because drops exposed to the atmosphere partially evaporated during transfer to the refractometor. This made it very difficult to obtain reproducible results.

In analyzing salt-saturated samples, some authors $(20,71)$ first separated the salt from the liquid samples, and then analyzed the salt-free liquids; others $(15,70)$ determined its density at a known temperature; while at least one author (1I) determined the refractive index of a binary liquid mixture saturated with a salt.

In this work, the analyses of salt-saturated liquid samples were accomplished by refractive index masurements. A calibration curve for the methanol-toluene system 
saturated with sodium bromide was prepared at $25^{\circ} \mathrm{C}$. The system methanol-toluene saturated with sodium bromide may be suitably analyzed by refractive index masurements. In the first place sodium bromide is not excessively soluble in the system methanol-toluene (64). Thus precipitation of sodium bromide on the refractometer prisms would not cause difficulties provided the prisms are properly cleaned and dried after each analysis. Secondly, the methanoltoluene mixtures saturated with sodium bromide are optically clear over the whole range of compositions. Hence they can be analyzed by refractive index measuraments (51). In order to obtain refractive index-composition data, mixtures of methanol and toluene were accurately weighed in ten ml. Weld-type specific gravity bottles. Hypodermic syringes were used when necessary to inject the required amounts of the liquids into the bottles. The weighing instrument was a Sartorius Balance. The compositions of the samples were first chacked by measuring their refractive indices at $25^{\circ} \mathrm{C}$. The solutions were then saturated with sodium bromide and kept in the constant tamperature bath at $25^{\circ} \mathrm{C}$. for several hours for thermal -quilibrium to be reached.

The results of this work together with the refractive index of methanol-toluene solutions are plotted in Figure 2. The plot for the salt-saturated system is on a salt-free basis. The experimental data of refractive index of methanol-toluene-sodium bromide solutions at

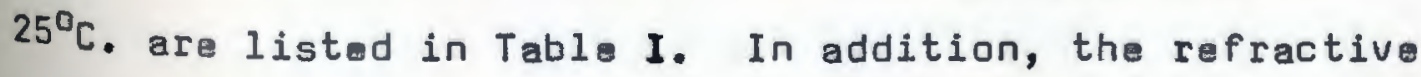




\section{FIGURE 2}

REFRACTIVE INDICES OF MIXTURES OF METHANOL AND TOLUENE AT $25^{\circ} \mathrm{C}$. (EXPERIMENTAL DATA) 


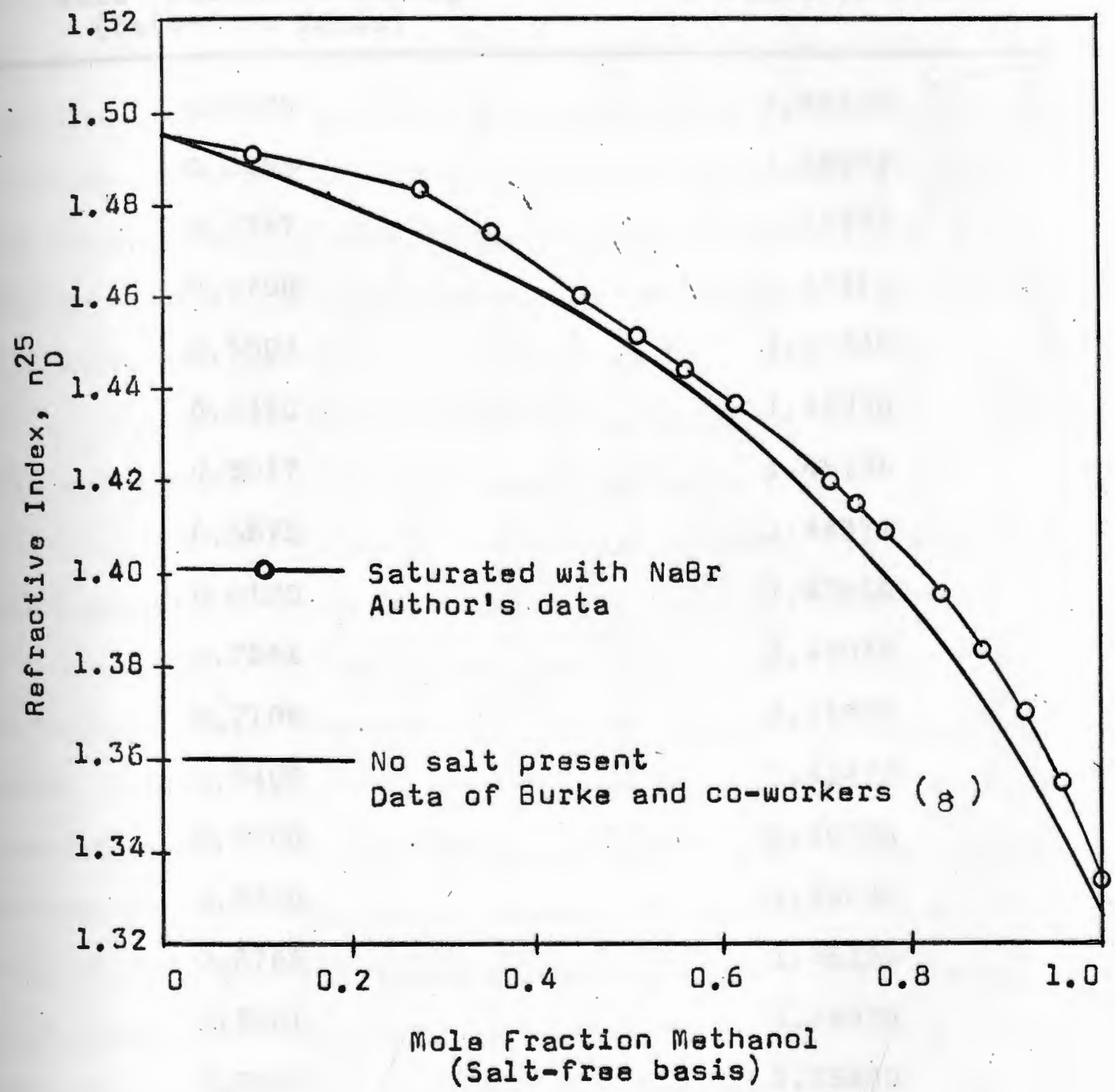


TABLE I

REFRACTIVE INDEX-COMPOSITION DATA AT $25^{\circ} \mathrm{C}$. FOR METHANOL-TOLUENE SOLUTIONS SATURATED WITH SODIUM BROMIDE

Mole Fraction Methanol

(salt-free Basis)

$\begin{array}{ll}0.0000 & 1.49430 \\ 0.0953 & 1.48972 \\ 0.2727 & 1.48272 \\ 0.2780 & 1.48210 \\ 0.3504 & 1.47340 \\ 0.4420 & 1.45930 \\ 0.5017 & 1.45106 \\ 0.5575 & 1.44371 \\ 0.6100 & 1.43610 \\ 0.7061 & 1.42045 \\ 0.7100 & 1.41990 \\ 0.7400 & 1.41470 \\ 0.7700 & 1.40890 \\ 0.8300 & 1.39520 \\ 0.8769 & 1.38330 \\ 0.9201 & 1.36970 \\ 0.9603 & 1.35400 \\ 1.0000 & 1.33260\end{array}$


index composition data for methanol-toluene solutions at $25^{\circ} \mathrm{C}$. are given in Table VIII in the Appendix. These data are those reported by Burke and co-workers (B).

Gas Ghromatography was seriously considered as a mathod of analysis since it has definite advantages for binary liquid mixtures saturated with inorganic salts. An obvious advantage is that, since the salt is non-volatile, only one calibration curve would be required to analyze the liquid and the vapor samples. Refractive index measurement was chosen over gas chromatography for the following reasons:

1. A refractive index-composition calibration curve for methanol-toluene was already available.

2. The refractive index measurements were simpler and quicker than gas chromatography.

3. Gas chromatography is not as accurate as refractive index measurement. Lu et al. (38) estimated an orror of \pm 0.2 mole\% using a Bausch and Lomb Abbe-3L precision refractometer and an error of $\pm 0.5 \mathrm{~mol}$ o\% using a Parkin-Elmer Model 154-C Vapor Fractomater. Bowden (6), however, thought the error-estimate on the Perkin-Elmer instrument was optimistic, and suggested a minimum error of $2-5 \%$. 


\section{Experimental Procedure}

Performance tests such as ability to reproduce data for wel1-known binary systems, approach to steady-state, and liquid entrainment tests were conducted. Equilibrium points were determined for ethanol-water and methanoltoluene systems at atmospheric pressure. The values obtained checked very well with those presented by chu (14), and those of Burke et al. (8).

\section{Charging the still}

The still was charged with approximately $300 \mathrm{ml}$. of solution in ach run. Saturation was assured by adding enough salt so that an excess was always observed at the bottom of the still. Initially the still was charged with approximately $250 \mathrm{ml}$. of pure methanol. Then the concentration of the mixture was varied by adding toluene or mothanol to the mixture from the previous run. For higher methanol concentrations, the alcohol and salt were added directly to the still. For higher toluene concentrations, it was necessary to empty the contents of the still into a beaker, add the toluene and reintroduce the mixture into the still, leaving some of the salt in the beaker. In this way, the salt precipitated when toluene is added is prevented from plugging the liquid sample cock. The still was operated for at least four hours to insure the attainment of quilibrium. The critarion for equilibrium was a constant temperature for the particular run. During this study the vapors were superheated by $5-10^{\circ} \mathrm{C}$. by supplying heat to the insulated portion of the still so that no rofluxing would be observed in the vapor channel. 


\section{Pressure Control}

Atmospheric pressure was measured by means of a mercury column barometar located in the same building as the apparatus. The pressure in the still was adjusted to $760 \mathrm{~mm} \mathrm{Hg}$ with the manostat. Pressure was controlled only after the addition of all components, and after it had been established that the mixture was saturated. With the pressure adjusted and no abnormal behavior such as leakage observed in the system, the timing of the experimental run was begun.

\section{Temperature Measurements}

Vapor temperatures in the still were measured with a mercury-in-glass thermometer calibrated against an A.S.T.M. thermometer. The thermometer was read at frequent intervals throughout the course of oach run in order to keep track of the approach of the system to equilibrium. In most cases the temperature remained constant after the still had been operated for about two hours. It was then allowed to run for another two hours before samples were takøn.

\section{Sampling Technique}

After the minimum time of four hours had -lapsed, the following standard procedure was followed for taking the samples:

1. Clean sample bottles were taken from the oven and allowed to cool in a desiccator at room temperature. 2. The sample outlets were cleaned and dried with a pipe cleaner. 
3. All heating elements ware turned off.

4. The system was vented to the atmosphere.

5. About ten $\mathrm{ml}$. of the condensate were drained off in order to flush the stopcock bore.

6. The vapor sampl bottle was immersed in an ice bath. About $10 \mathrm{ml}$. of condensate were collected and the sample bottle was immediately stoppered and labelled.

7. Approximately $20 \mathrm{ml}$. of liquid were drained from the still-pot in order to flush the stopcock bore.

8. Sodium bromide was introduced into the liquid sample bottle. This was to ensure that the liquid samples would still be saturated.

9. The liquid sample bottle was immersed in an ice bath. About $20 \mathrm{ml}$. of liquid sample were collected, and the bottle was immediately stoppered and labelled.

10. Both samples were refrigerated until they were transferred to the constant temperature bath. By strictly following the above procedure, the errors introduced by sampling were reduced to a minimum.

5. Refractive Index Measurement

The samples were analyzed as soon as possible after completion of a run. The samples were left overnight in the constant tomperature bath in order to ensure thermal equilibrium and saturation of the liquid sample. In very run the vapor sample was analyzed before the liquid sample. The refractometer prisms were carefully washed with methyl alcohol, allowed to dry, and cleaned with lens paper. Any specks of foreign material were removed with camel-hair brush. 


\section{EXPERIMENTAL RESULTS}

\section{A. Experimental Vapor-Liquid Equilibrium Data}

The following factors were determined experimentally for each run: duration of run, total pressure, vapor composition expressed as mole fraction methanol, and liquid composition expressed as mole fraction methanol on a salt-free basis. Those values are given in Table II. The equilibrium data for the system methanol-toluene saturated with sodium bromide are shown in Figure 3 . The data obtained for methanol-toluene by Burke et al. (8), listed in Table VII in the Appendix, are also plotted on the same curve for comparison. 


\section{TABLE II}

EXPERIMENTAL VAPOR-LIQUID EQUILIBRIUM DATA OF METHANOL-TOLUENE-SODIUM BROMIDE SYSTEM (under Helium)

\begin{tabular}{|c|c|c|c|c|}
\hline Run No. & $\begin{array}{l}\text { Duration of } \\
\text { Run, Hours }\end{array}$ & $\begin{array}{c}\text { Total Pressure } \\
\text { mm } \mathrm{Hg}\end{array}$ & $\begin{array}{c}\text { Mole } \\
\text { Liquid } \\
x_{1}\end{array}$ & $\begin{array}{r}\text { raction } \\
\text { Vapor } \\
\end{array}$ \\
\hline $1-5$ & Preliminary & Runs & & \\
\hline 6 & 6.0 & $760 \pm 2.0$ & 0.912 & 0.877 \\
\hline 7 & 6.5 & $760 \pm 2.0$ & 0.930 & 0.905 \\
\hline 8 & 5.5 & $760 \pm 2.0$ & 0.953 & 0.939 \\
\hline 9 & 5.5 & $760 \pm 2.0$ & 0.343 & 0.783 \\
\hline 10 & 5.5 & $760 \pm 2.0$ & 0.011 & 0.051 \\
\hline 11 & 6.0 & $760 \pm 2.0$ & 0.288 & 0.770 \\
\hline 12 & 5.0 & $760 \pm 2.0$ & 0.121 & 0.721 \\
\hline 13 & 5.0 & $760 \pm 2.0$ & 0.155 & 0.731 \\
\hline 14 & 4.5 & $760 \pm 2.0$ & 0.600 & 0.821 \\
\hline 15 & 6.0 & $760 \pm 2.0$ & 0.517 & 0.813 \\
\hline 16 & 4.5 & $760 \pm 2.0$ & 0.690 & 0.824 \\
\hline 17 & 5.5 & $760 \pm 2.0$ & 0.829 & 0.840 \\
\hline 18 & 6.0 & $760 \pm 2.0$ & 0.888 & 0.860 \\
\hline 19 & 7.0 & $760 \pm 2.0$ & 0.926 & 0.892 \\
\hline 20 & 6.0 & $760 \pm 2.0$ & 0.886 & 0.858 \\
\hline 21 & 6.0 & $760 \pm 2.0$ & 0.446 & 0.814 \\
\hline 22 & 6.5 & $760 \pm 2.0$ & 0.018 & 0.144 \\
\hline 23 & 6.5 & $760 \pm 2.0$ & 0.071 & 0.560 \\
\hline 24 & 6.0 & $760 \pm 2.0$ & 0.120 & 0.690 \\
\hline 25 & 6.0 & $760 \pm 2.0$ & 0.032 & 0.214 \\
\hline 26 & 6.5 & $760 \pm 2.0$ & 0.095 & 0.660 \\
\hline
\end{tabular}


FIGURE 3

VAPOR-LIQUID EQUILIBRIUM CURVE FOR METHANOL-TOLUENE SYSTEM

( EXPERIMENTAL DATA) 


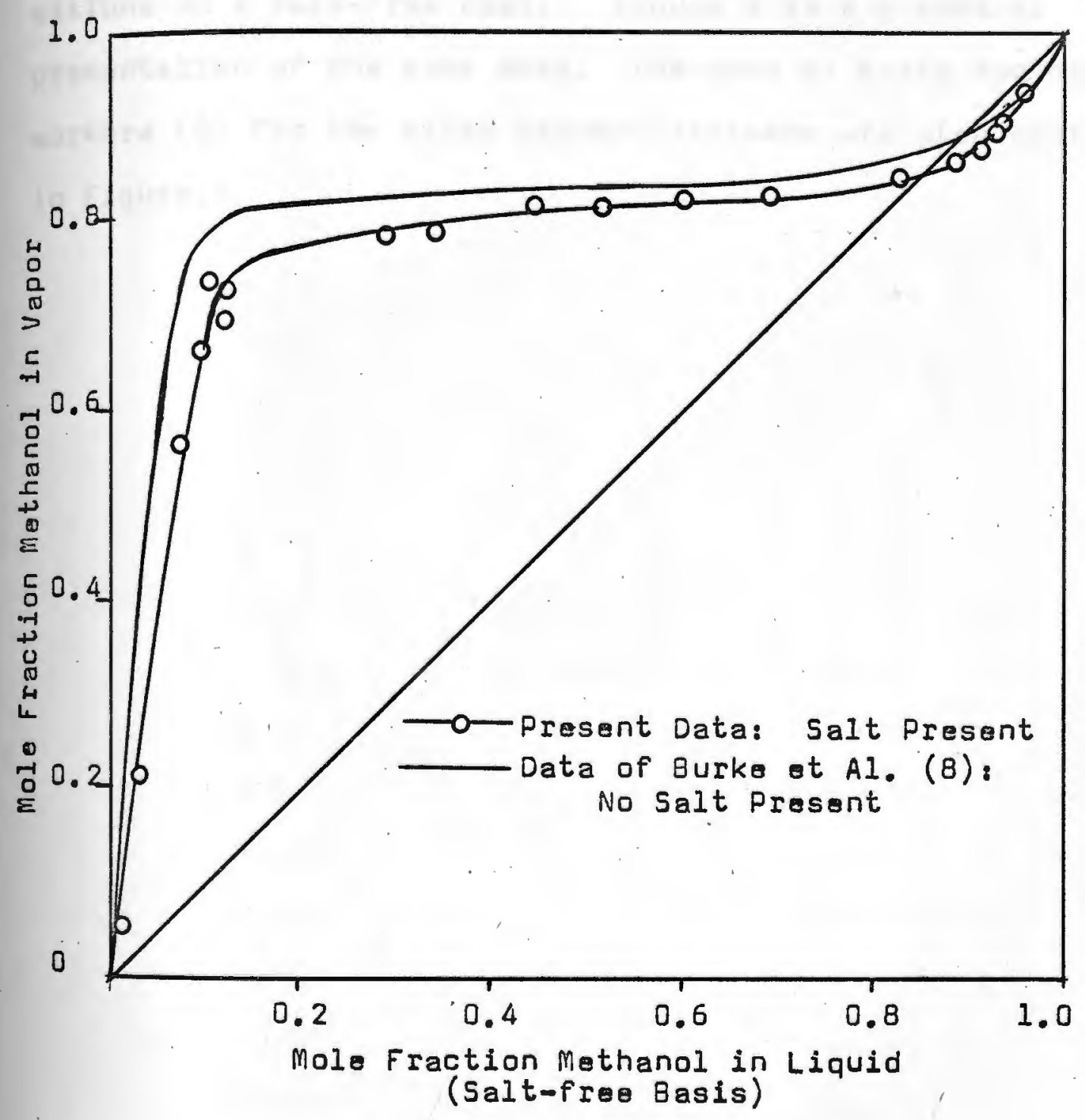


B. Boiling Point-Composition Data

The experimental boiling point data for methanoltoluene mixtures saturated with sodium bromide are presented in Table III with the corresponding liquid compositions on a salt-free basis. Figure 4 is a graphical presentation of the same data. The data of Burke and coworkers ( $B$ ) for the ystem methanol-toluene are also plotted in Figure 4. 
TABLE III

\section{BOILING POINTS AT ATMOSPHERIC PRESSURE OF METHANOL-TOLUENE SOLUTIONS SATURATED WITH SODIUM BROMIDE}

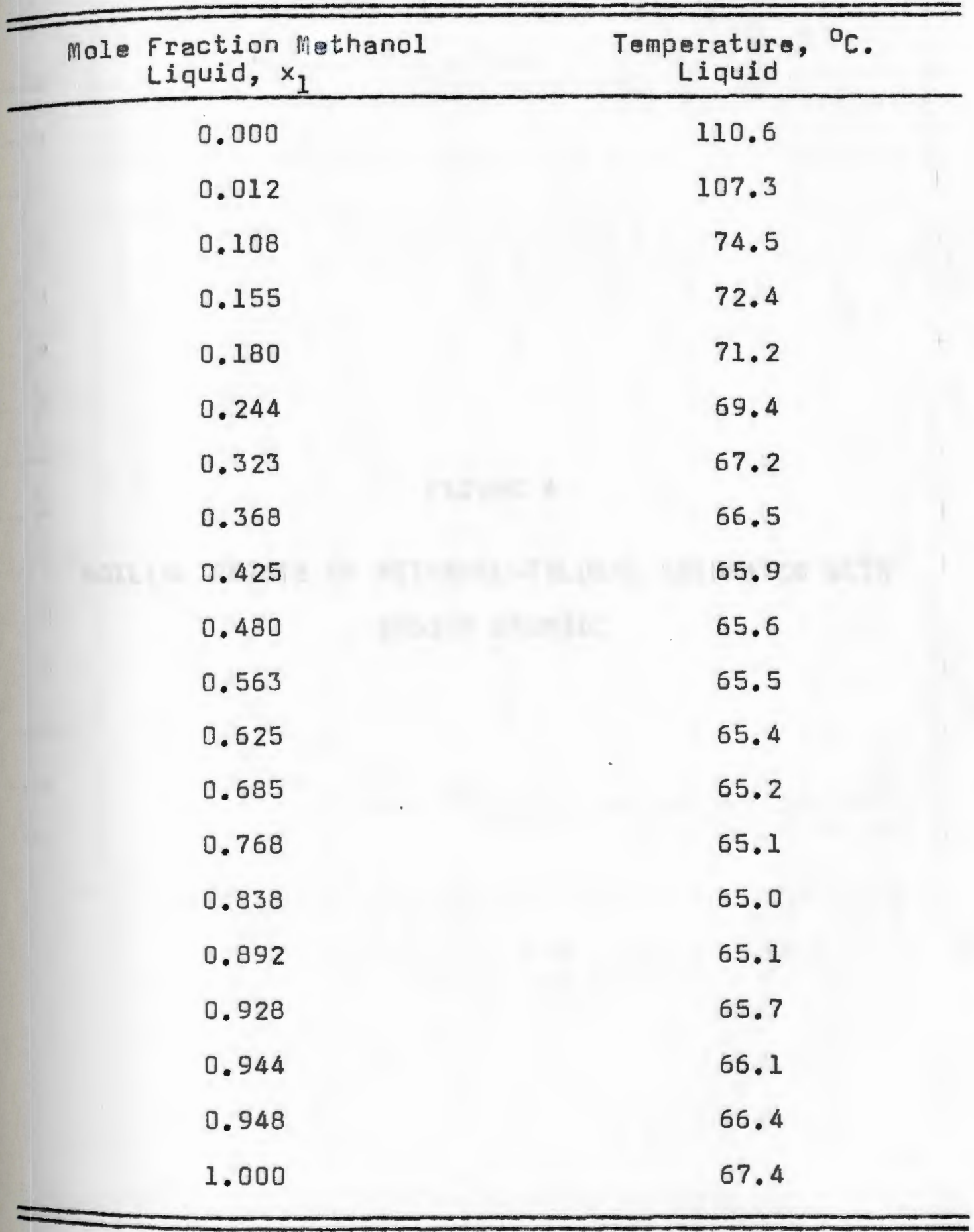


FIGURE 4

BOILING POINTS OF METHANOL-TOLUENE SATURATED WITH SODIUM BROMIDE 


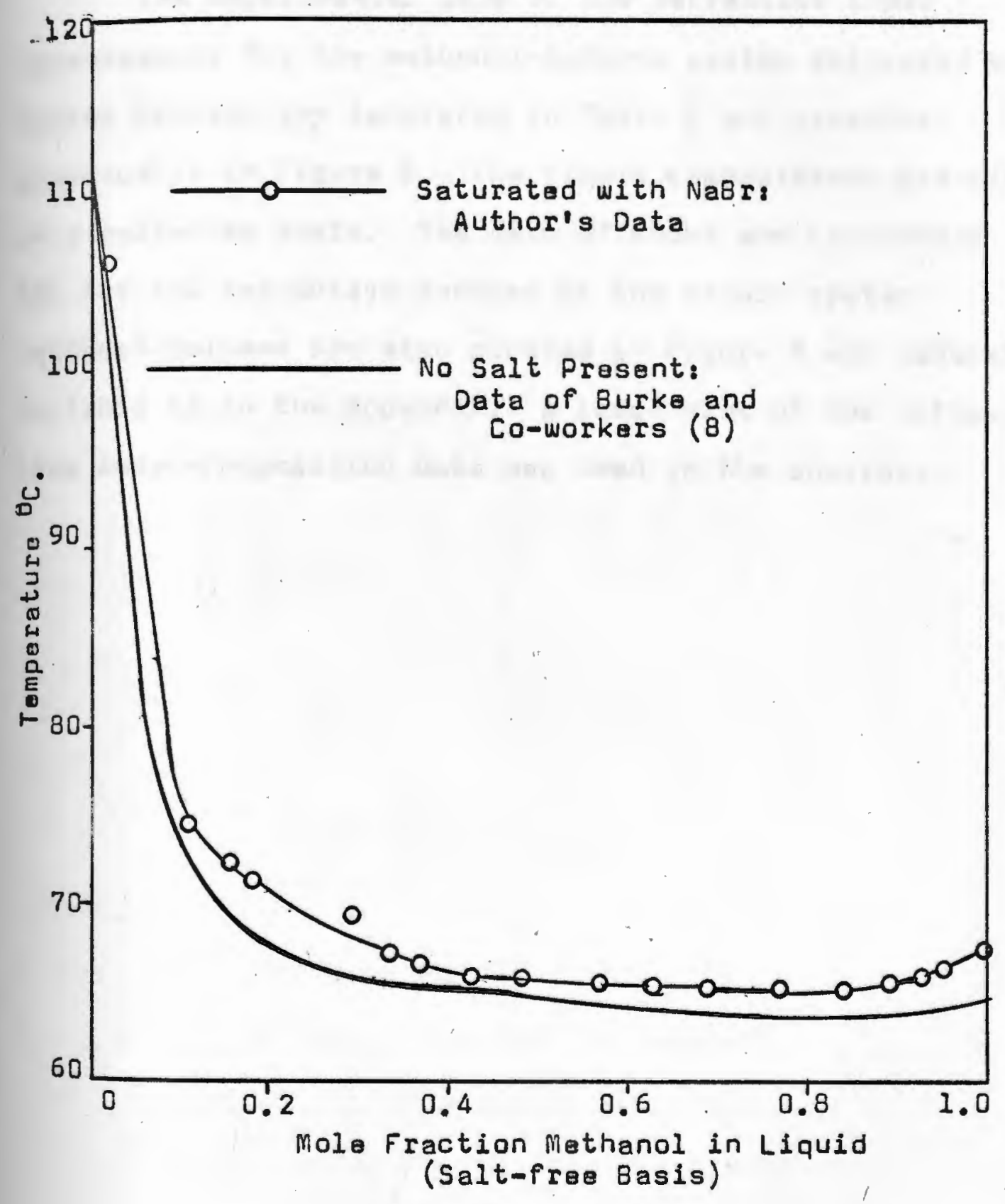


C. Rafractive Index-Composition Data at $25^{\circ} \mathrm{C}$.

The experimental data of the refractive index measurements for the methanol-toluene system saturated with sodium bromide are tabulated in Table I and presented graphically in Figure 2. The liquid compositions are given on a salt-free basis. The data of Burke and co-workers (B) for the refractive indices of the binary system methanol-toluene are also plotted in Figure 2 and tabulated in Table $X I$ in the Appendix. A large plot of the refractive index-composition data was used in the analysis. 


\section{CALCULATED RESULTS}

A. Mole Eraction

In order to prepare the refractive index-composition calibration curve, solutions of methanol and toluene of accurately known compositions wer saturated with sodium bramide. The compositions, initially expressed as wight fraction methanol on a salt-fre basis were converted to the corresponding mole-fractions. The mole fractions were calculated from the wilght fractions by the following relation:

$$
\begin{aligned}
x_{\text {MeOH }} & =\frac{\frac{x_{\text {MeOH }}}{32.04}}{\frac{x_{\text {MeOH }}}{32.04}+\frac{\left(1-x_{\text {MeOH }}\right)}{92.13}} \\
& =\frac{x_{\text {MeOH }}}{0328+0.672 x_{\text {MeOH }}}
\end{aligned}
$$

where

$$
\begin{aligned}
& x_{\mathrm{MeOH}}=\text { mole fraction of methanol } \\
& x_{\mathrm{HeOH}}=\text { weight fraction of methanol } \\
& 32.04=\text { molecular weight of methanol } \\
& 92.13=\text { molecular weight of toluene }
\end{aligned}
$$




\section{B. Relative Volatility}

The volatility of any substance in a homogenoous liquid is defined as its partial pressure in the vapor in equilibrium with that liquid, divided by its mole fraction in the liquid (60). The relative volatility of a mixture is the ratio of the volatilities of the components. For a binary mixture containing components $A$ and $B$, the relative volatility is defined as:

$$
\begin{aligned}
\alpha_{A B} & =\frac{v_{A}}{v_{B}} \\
& =\frac{\frac{p_{A}}{x_{A}}}{\frac{p_{B}}{x_{B}}}
\end{aligned}
$$

If the vapor phase is assumed to follow Dalton's law of partial pressures, the final expression for the relative volatility is:

$$
\alpha_{A B}=\frac{y_{A} x_{B}}{x_{A} y_{B}}
$$

where

$$
\begin{aligned}
\alpha_{A B} & =\text { volatility of "A" with respect to "B" } \\
x & =\text { mole fraction in the liquid phase } \\
y & =\text { mole fraction in the vapor phase } \\
A & =\text { lower boiling component } \\
B & =\text { higher boiling component } \\
v_{A} & =\text { volatility of "A" } \\
v_{B} & =\text { volatility of "B" }
\end{aligned}
$$

Relative volatility is a direct measure of the ease of separation of two or more components by the distillation process. The more separable a mixture is the larger is 
the value of the relative volatility. If the relative volatility, $\alpha$, is unity, no separation is possible since the composition of the liquid is identical with that of the vapor.

$$
\text { Relative volatilities were calculated from the }
$$
experimental oquilibrium data for the system methanoltoluene saturated with sodium bromide. The calculated values are listed in Table IV. The values calculated for the binary system methanol-toluene according to the data of Burke et al. (8), are listed in the Appendix in Table XII. Both sets of data are plotted in Figure 5. 
TABLE IV

RELATIVE VOLATILITIES OF METHANOL-TOLUENE SATURATED WITH SODIUM BROMIDE

\begin{tabular}{|c|c|c|}
\hline Mole Fraction & Methanol & Relative Volatility \\
\hline$x_{1}$ & $y_{1}$ & \\
\hline 0.912 & 0.877 & 0.687 \\
\hline 0.930 & 0.905 & 0.715 \\
\hline 0.953 & 0.939 & 0.758 \\
\hline 0.343 & 0.783 & 6.945 \\
\hline 0.011 & 0.051 & 5.000 \\
\hline 0.288 & 0.770 & 8.303 \\
\hline 0.121 & 0.721 & 19.181 \\
\hline 0.155 & 0.731 & 15.048 \\
\hline 0.600 & 0.821 & 3.065 \\
\hline 0.517 & 0.813 & 4.083 \\
\hline 0.690 & 0.824 & 2.107 \\
\hline 0.829 & 0.840 & 1.083 \\
\hline 0.888 & 0.860 & 0.774 \\
\hline 0.926 & 0.892 & 0.660 \\
\hline 0.886 & 0.858 & 0.776 \\
\hline 0.446 & 0.814 & 5.350 \\
\hline 0.018 & 0.144 & 9.400 \\
\hline 0.071 & 0.560 & 16.774 \\
\hline 0.120 & 0.690 & 16.405 \\
\hline 0.032 & 0.214 & 8.280 \\
\hline 0.095 & 0.660 & 18.656 \\
\hline
\end{tabular}


FIGURE 5

RELATIVE VOLATILITY OF METHANOL-TOLUENE MIXTURES 


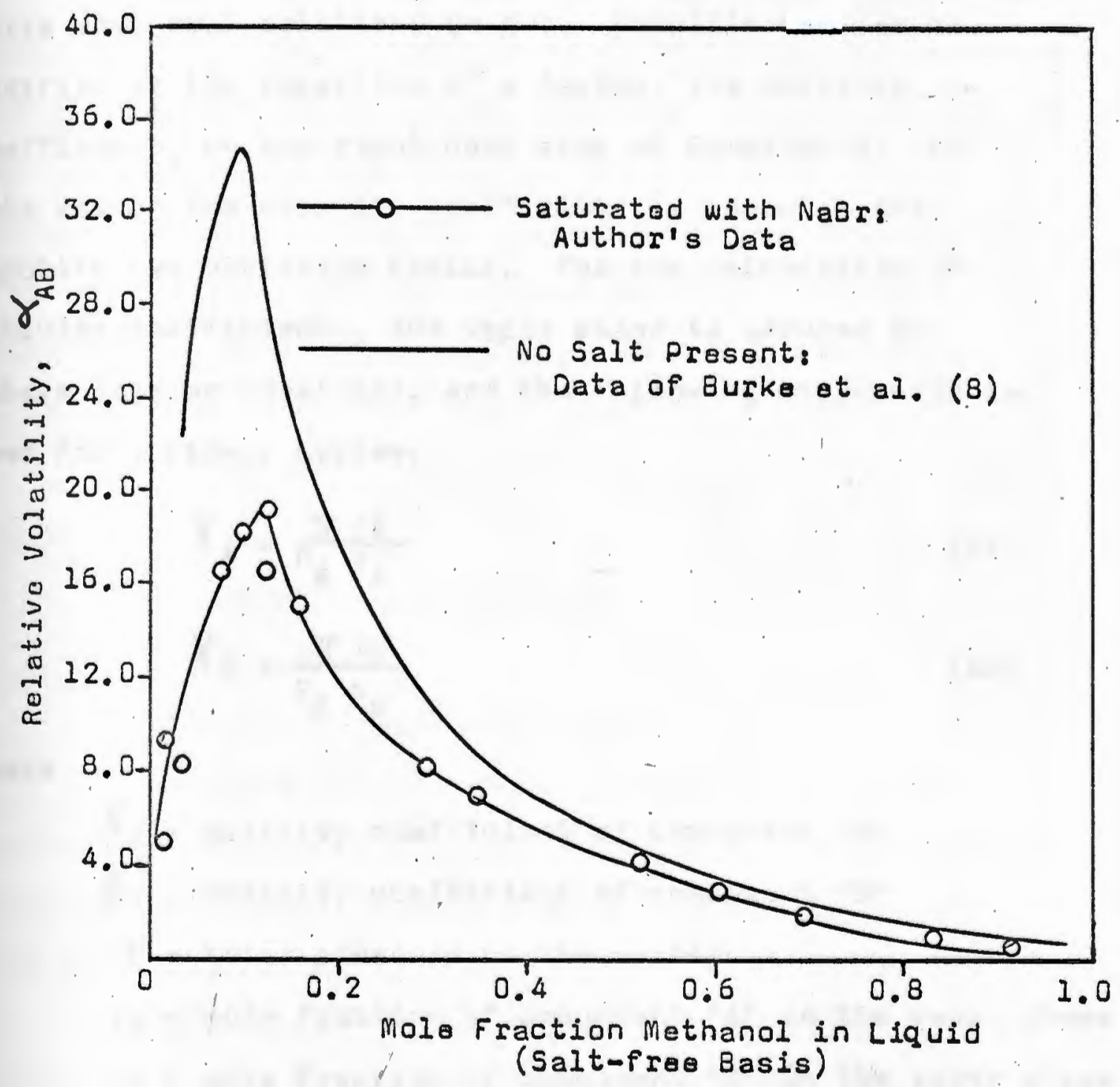




\section{Activity Coefficients}

The activity coefficients of a system are used to compare the properties of real solutions with those of an ideal solution (27). Ideal solutions follow Raoult's Law while most real solutions do not. Raoult's Law can be modified by the insertion of a factor, the activity coefficient, on the right hand side of Equation 6. For this reason the activity coefficient is known as the Raoult's Law Deviation Factor. For the calculation of activity coefficionts, the vapor phase is assumed to behave like an ideal gas, and the following expression is used for a binary system:

$$
\begin{aligned}
& \gamma_{A}=\frac{\pi y_{A}}{P_{A} x_{A}} \\
& \gamma_{B}=\frac{\pi y_{B}}{P_{B} x_{B}}
\end{aligned}
$$

where

$$
\begin{aligned}
& \gamma_{A}=\text { activity coefficient of component "A" } \\
& \gamma_{B}=\text { activity coefficient of component "B" } \\
& \pi=\text { total pressure on the system } \\
& y_{A}=\text { mole fraction of component "A" in the vapor phase } \\
& y_{B}=\text { mole fraction of component "B" in the vapor phase } \\
& P_{A}=\text { vapor pressure of pure component "A" at the } \\
& \quad \text { temperature for which the equilibrium data } \\
& \text { were determined } \\
& P_{B}=\text { vapor pressure of pure component "B" at the } \\
& \quad \text { temperature for which the equilibrium data } \\
& \text { were determined }
\end{aligned}
$$




$$
\begin{aligned}
& x_{A}=\text { mole fraction of component "A" in the liquid } \\
& \text { phase } \\
& x_{B}=\text { mole fraction of component "B" in the liquid } \\
& \text { phase }
\end{aligned}
$$

Vapor pressure data for both methanol and toluene ware obtained from Chemical Engineers' Handbook (51). In Figure 6 the logarithms of the vapor pressures are plotted against the reciprocals of the absolute temperatures. The reciprocals of the absolute temperatures have been multiplied by $10^{3}$ for convenience in plotting. Since the temperature range is not too wide, these data follow the Equation (17):

$$
\log P=A+\frac{B}{T}
$$

where

$$
P=\text { vapor pressure in } \mathrm{mm} \mathrm{Hg}
$$

$A$ and $B=$ constants

$$
T=\text { absolute temperature in } \mathrm{O}_{\mathrm{K}}
$$

By presenting the graphical dependence of vapor pressure on temperature in such a way that a straight line is obtained, vapor pressures can be read off the graph with greater accuracy.

The calculated values of the activity coefficients for the system methanol-toluene saturated with sodium bromide are listed in Table $V$ and plotted in Figure 7. The activity coefficients reported for the system methanoltoluene by Burke and co-workers are listed in Table IX in the Appendix and plotted in Figure 7. 
FIGURE 6

VAPOR PRESSURES OF METHANOL AND OF TOLUENE 


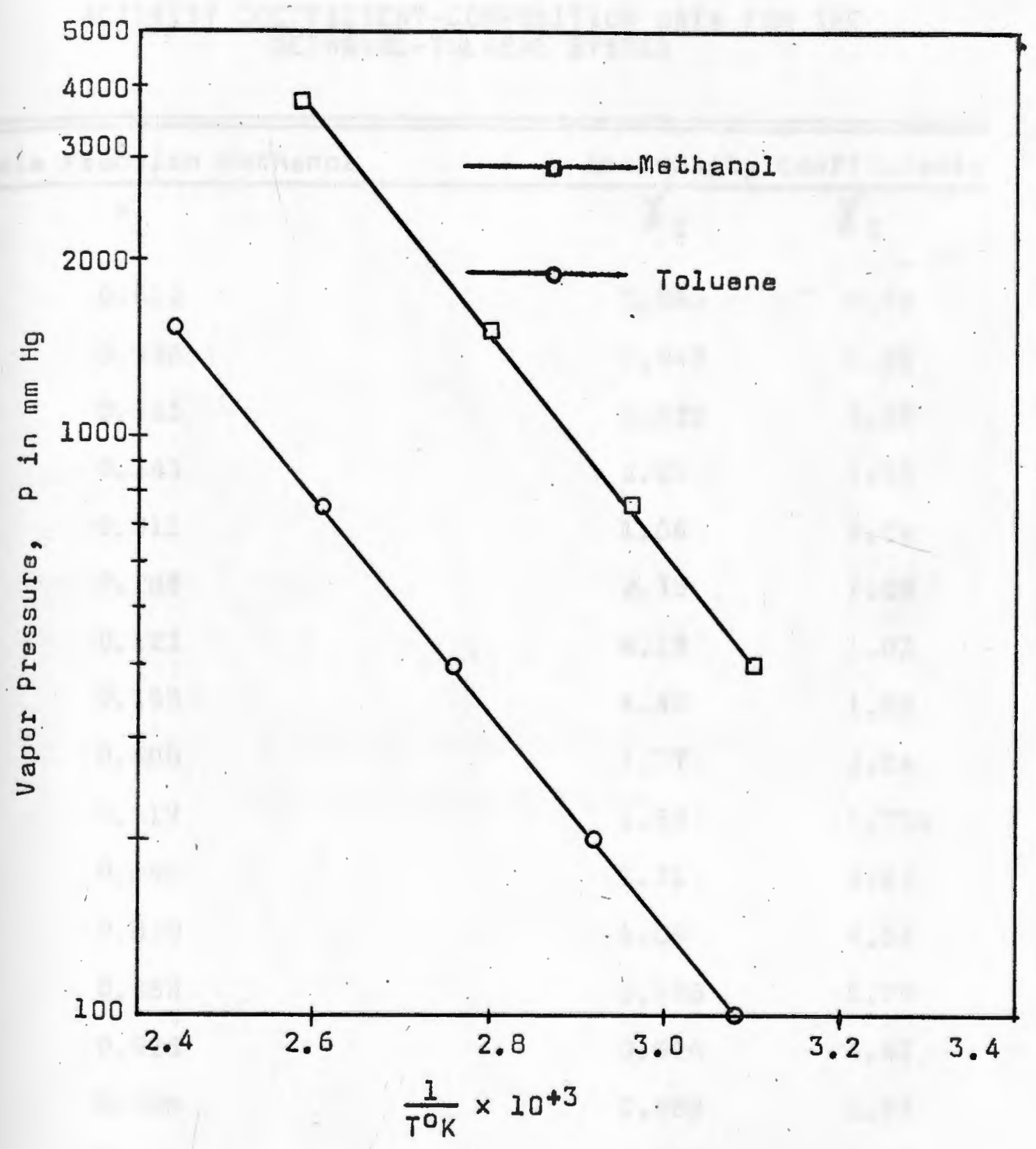


TABLE V

ACTIVITY COEFFICIENT-COMPOSITION DATA FOR THE METHANOL-TOLUENE SYSTEM

Mole Fraction Methanol

Activivity Coefficients

$x_{1}$

$\gamma_{1}$

$\gamma_{2}$

0.912

0.963

6.36

0.930

0.947

6.06

0.953

0.925

5.59

0.343

2.05

1.36

0.011

1.06

1.04

0. 288

2.35

1.09

0.121

4.19

1.03

0.155

4.48

1.08

0.600

1.37

2.04

0.517

1.54

1.730

0.690

1. 21

2.62

0.829

1.09

4.34

0.888

0.986

5.79

0.926

0.926

6.41

0.886

0.968

5.74

0.446

1.950

1.48

0.018

2.150

1.09

0.071

3.960

1.08

0.120

4.270

1.19

0.032

2.110

1.11

0.055

4.55

1.07 
FIGURE 7

ACTIVITY COEFFICIENT-COMPOSITION CURVES FOR METHANOL-TOLUENE SYSTEM 


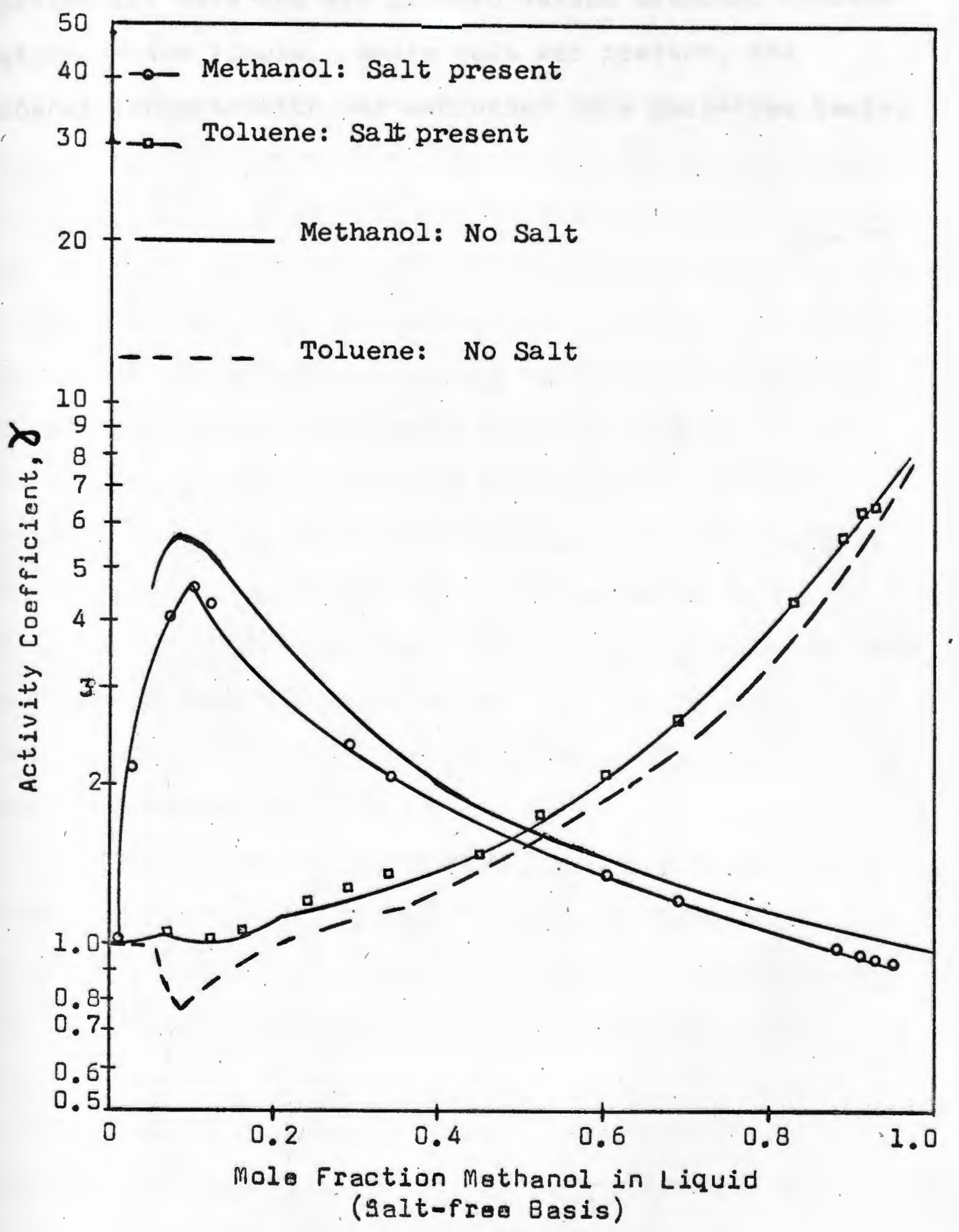


In both cases the activity coefficients wer based on actual experimental data and are plotted versus methanol concentration in the liquid. Where salt was present, the methanol concentration was expressed on a salt-free basis. 


\section{TEST FOR THERMODYNAMIC CONSISTENCY}

The experimental data were tested for thermodynamic consistency. The shapes and smoothness of the vapor-liquid equilibrium plot, Figure 3 , and the activity coefficients plot, Figure 7, were criteria for thermodynamic consistency. In Figure 8 , the in $\gamma_{1}$ curve exhibits a maximum at approximately 0.10 mole fraction methanol while the $\ln \gamma_{2}$ curve exhibits a minimum at 0.12 mole fraction methanol.

Burke and co-workers ( 8 ) state that at a concentration of 0.5 mole fraction the value of ${ }_{1 n} \gamma_{I}$ should be greater than that of $\ln \gamma_{2}$, since the value of $\ln _{2} \gamma_{2}$ at $x_{1}=1.0$ is greater than that for $\ln _{2}$ at $x_{1}=0$. In this investigation the opposite was found to be the case. The values obtained for in $\gamma_{1}$ and in $\gamma_{2}$ at $x_{1}=0.5$ were 0.438 and 0.525 , respectively.

An additional thermodynamic check was made of the experimental data using a modification of the method of Redlich and Kister (56). The Redich-Kister equation which is given below applies only to isothermal data.

$$
\int_{0}^{1} \ln \frac{\gamma_{1}}{\gamma_{2}} d x_{1}=0
$$

Herington (28) extended the method to include isobaric data. In this case the integral of Equation $B$ above does not equal zero and the condition necessary for thermodynamic cansistency is:

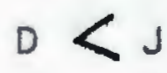


where $D$ is the percentage deviation from zero of the quantity calculated in Equation 8. D is calculated as follows:

$$
0=\frac{100\left|\int_{0}^{1} \ln \frac{\gamma_{1}}{\gamma_{2}} d x_{1}\right|}{\left|\sum_{\text {Area }}\right|}
$$

where $\left|\sum\right|$ is the sum of the absolute values of the areas calculated by Equation 8. The quantity $J$ is a function of the over-all boiling point range of the system and is defined by the following equation:

$$
J=\frac{150 \quad \theta}{T_{\text {min }}}
$$

where $\theta$ is the over-all range of boiling points of the system and $T_{m i n}$ is the lowest measured boiling point of the system in degrees Kelvin.

For the mothanol-toluene-sodium bromide systam investigated in this study, $D=13.9$ and $J=19.2$. Hence tho data ar thermodynamically consistent. Calculated values of $\frac{\gamma_{1}}{\gamma_{2}}$ are listed in Table VI. Figure $\theta$ is a plot of $\log \frac{\gamma_{1}}{\gamma_{2}}$ versus $x_{1}$. 
TABLE VI

VALUES CALCULATED FOR THERMODYNAMIC CONSISTENCY TEST

\begin{tabular}{|c|c|c|c|}
\hline$x_{1}$ & $\gamma_{1}$ & $\gamma_{2}$ & $\frac{81}{82}$ \\
\hline 0.011 & 1.06 & 1.04 & 1.019 \\
\hline 0.018 & 2.15 & 1.09 & 1.973 \\
\hline 0.032 & 2.11 & 1.11 & 1.901 \\
\hline 0.071 & 3.96 & 1.08 & 3.667 \\
\hline 0.095 & 4.55 & 1.07 & 4.252 \\
\hline 0.120 & 4.27 & 1.19 & 3.588 \\
\hline 0.121 & 4.19 & 1.03 & 4.068 \\
\hline 0.155 & 4.48 & 1.08 & 4.148 \\
\hline 0.288 & 2.35 & 1.29 & 1.822 \\
\hline 0.343 & 2.05 & 1.36 & 1.507 \\
\hline 0.446 & 1.95 & 1.48 & 1.318 \\
\hline 0.517 & 1.54 & 1.73 & 0.890 \\
\hline 0.600 & 1.37 & 2.04 & 0.672 \\
\hline 0.690 & 1.21 & 2.62 & 0.462 \\
\hline 0.829 & 1.09 & 4.34 & 0.251 \\
\hline 0.886 & 0.968 & 5.74 & 0.169 \\
\hline 0.888 & 0.986 & 5.79 & 0.170 \\
\hline 0.912 & 0.963 & 6.36 & 0.151 \\
\hline 0.926 & 0.926 & 6.44 & 0.145 \\
\hline 0.930 & 0.946 & 6.06 & 0.156 \\
\hline 0.953 & 0.925 & 5.59 & 0.165 \\
\hline
\end{tabular}


FIGURE 8

PLOT FOR THERMODYNAMIC CONSISTENCY TEST 


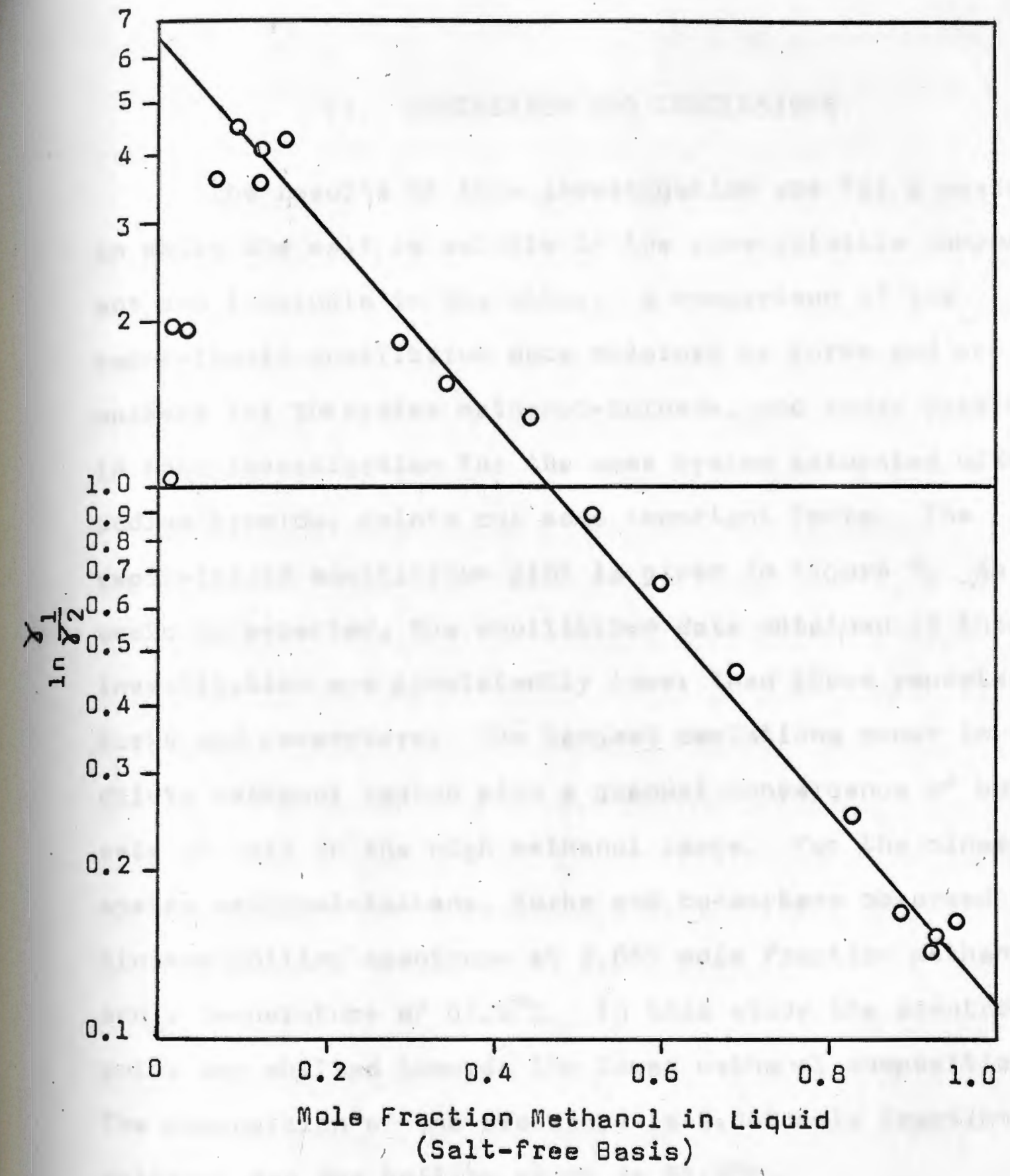




\section{DISCUSSION AND CONCLUSIONS}

The results of this investigation are for a system in which the salt is soluble in the mor volatile component and insoluble in the other. A comparison of the vapor-liquid equilibrium data obtained by Burke and coworkers for the system methanol-toluene, and those obtained in this investigation for the same system saturated with sodium bromide, points out some important facts. The vapor-liquid equilibrium plot is given in Figure 3. As would be expected, the equilibrium data obtained in this investigation are consistently lower than those reported by Burke and co-workers. The largest deviations occur in the dilute methanol region with a gradual convergence of both sets of data in the high methanol range. For the binary system methanol-toluene, Burke and co-workers observed a minimum boiling azootrop at 0.885 mole fraction methanol and a temperature of $63.6^{\circ} \mathrm{C}$. In this study the azeotropic point was shifted towards the lower mathanol compositions. The composition of the azeotrope is 0.845 mole fraction methanol and the boiling point is $65.0^{\circ} \mathrm{C}$.

Figure 5 is a plot of the relative volatilities observed in this investigation and those calculated from the data of Burke t al. The graphs clearly show that the I lative volatility is appreciably decreased by the addition of salt. The trend observed is similar to that previously noted for the vapor-liquid quilbrium plot in 
Figure 3. The ffect of the salt is more pronounced at the low methanol compositions and the two curves approach each other as the methanol composition increases.

In Figure 7 the activity coefficients determined from the data of this investigation are plotted along with those determined by Burke and co-workers. The plot shows that the activity coefficients of both methanol and toluen decreased by a constant value over the entire composition rang as a result of the presence of the salt. The activity coefficient plot showed fairly smooth curves especially at high methanol compositions. At lower methanol compositions, however, the experimental points showed some scattaring. Scattering was observed in the vapor-liquid plot and relative volatility plot at low methanol compositions. The shape of the equilibrium curve explains why such scattering should be anticipated. A small change in liquid composition in this range results in a disproportionately large change in vapor composition. Thus in this range of compositions it is more difficult to determine liquid and vapor compositions to a high degree of accuracy. A comparison of the relative volatility plot, Figure 5, with the activity coefficients plat, Figure 7, indicates that the effect of the salt is greatest where non-ideality is greatest. This occurs at approximately 0.1 mole fraction methanol.

Comparison of the experimental results with Burke's data indicate that sodium bromide significantly affects the vapor-liquid equilibrium of methanol and toluene. As 
would be expected, the relative volatility of methanol with respect to toluene is decreased over the entire range of compositions. A comparison of the activity coefficients indicates that the presence of the salt makes the salt more ideal.

Although some scattering was observed in the low methanol range, satisfactory curves were obtained for the vapor-liquid equilibrium, boiling point-compositions, relative volatility, and activity coefficient plots. Moreover, the Redlich-Kister test showed the experimental data to be thermodynamically consistent. All this would then indicate that refractive index measurements can be reliably used not only to analyze binary organic mixtures but also mixtures saturated with salts. 
VII. SUGGESTIONS FOR FUTURE WORK

It is suggested that the effects of other salts on the system methanol-toluene at $760 \mathrm{~mm} \mathrm{Hg}$ should be investigated. Specifically, salts more soluble in methanol than sodium bromide should be amployed. Since it is possible that a salt very soluble in methanol would break the binary system into a two phase liquid system, it is suggested that an equilibrium still be used which is designed to allow sampling of a two phase liquid systam.

It would also be advantageous to investigate ways of increasing the relative volatility of the system methanoltoluene. This may have a direct industrial application if it breaks the azeotrops. In order to attempt to break the azeotrope, experimental vapor-liquid equilibrium data should be determined for the binary system methanol-toluene at lower pressures than atmospheric.

Finally, analysis of salt-saturated binary organic mixtures by refractive index measurements should be encouraged and used more widely in view of the many attendant advantages. There is a dearth of information in the literature concerning refractive index-composition data for ternary systems. More effort should be expended to fill this gap. 


\section{SUMMARY}

Refractive index-composition data for methanoltoluene saturated with sodium promide were obtained at $25^{\circ} \mathrm{C}$. and used in the analysis of the samples taken in this experiment.

Vapor-liquid quilibrium and boiling-point-composition data at $760 \mathrm{~mm} \mathrm{Hg}$ were obtained for the system methanol-toluene saturated with sodium bromide. An improved othmer type equilibrium still was used. From the experimental vapor-liquid equilibrium data, relative volatilities and activity coefficients were calculated. The effect of sodium bromide on the relative volatilities and activity coefficients of the system was shown and discussed. The experimental data were tested by the method of Redlich and Kister and found to be tharmodynamically consistent.

An extensive literature survey was made and a summary of the major published investigations on the subject of salt-effect in vapor-liquid equilibrium is presented in the Appendix and in the Bibliography. 


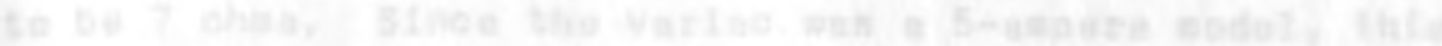

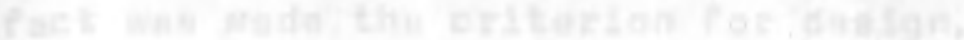

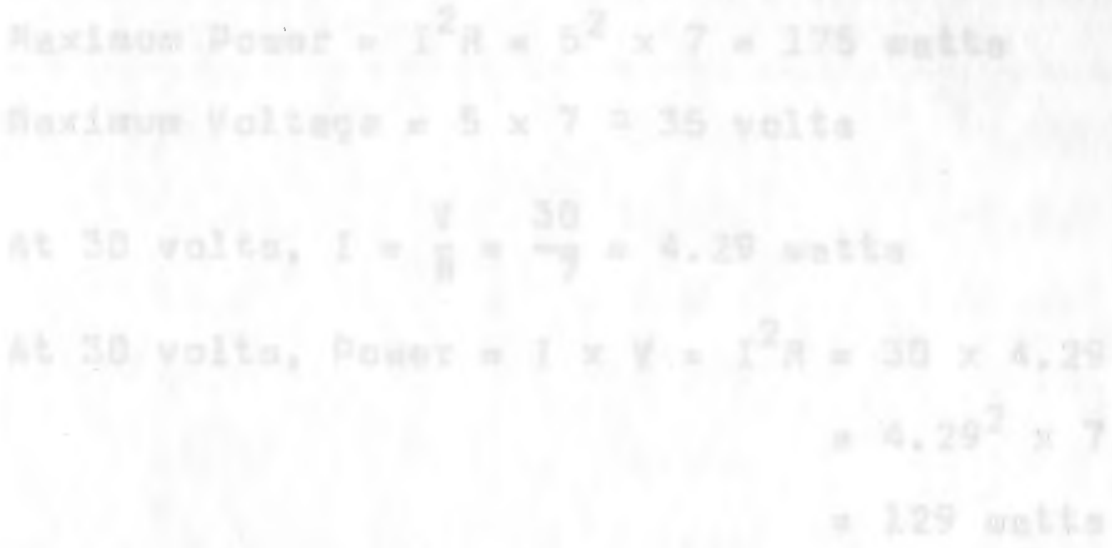

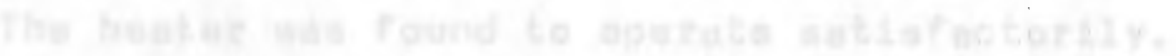

IX. APPENDIX 
Design of External Heater

Initially, the resistance of a wire was determined to be 7 ohms. Since the variac was a 5 -ampere model, this fact was made the criterion for design.

Maximum Power $=I^{2} R=5^{2} \times 7=175$ watts

Maximum Voltage $=5 \times 7=35$ volts

At 30 volts, $I=\frac{V}{R}=\frac{30}{7}=4.29$ watts

At 30 volts, Power $=I \times V=I^{2} R=30 \times 4.29$

$$
\begin{aligned}
& =4.29^{2} \times 7 \\
& =129 \text { watts }
\end{aligned}
$$

The heater was found to operate satisfactorily. 
TABLE VII

EXPERIMENTAL EQUILIBRIUM DATA FOR METHANOL-TOLUENE AT $760 \mathrm{~mm}$ of $\mathrm{Hg}$ (Burke t al.)

Temperature

${ }^{\circ} \mathrm{C}$.

110.6

89.90

84.80

80.40

74.75

71.30

69.70

66.75

65.75

65.10

64.15

63.70

63.60

63.70

64.10

64.60
Mole Fraction Methanol.

$$
y_{1}
$$

0.000

0.519

0.607

0.704

0.777

0.114

0.793

0.132

0.801

0.234

0.813

0.330

0.822

0.439

0.828

0.675

0.842

0.830

0.866

0.870

0.878

0.930

0.912

0.974

0.957

1.000

1.000 
TABLE VIII

REFRACTIVE INDICES OF MIXTURES OF METHANOL-TOLUENE AT $25^{\circ} \mathrm{C}$.

Mole Fraction methanol

0.0000

0.0967

0.2246

0.3507

0.4829

0.5312

0.6037

0.7025

0.7289

0.7663

0.8426

0.8861

0.9296

0.9685

1.000
Refractive Index

1.49428

1.48772

1.47775

1.46562

1.45033

1.44370

1. 43268

1. 41497

1.40986

1.40112

1.38158

1.36870

1.35390

1.33997

1.32691 
TABLE IX

ACT IVITY COEFFIC IENT-COMPOSITION DATA FOR METHANOL-TOLUENE (BUTKe ot al.)

Mole Fraction Methanol $x_{1}$

0.000

0.046

0.058

0.070

0.094

0.114

0.132

0.234

0.330

0.439

0.675

0.830

0.870

0.930

0.974

1.000
Activity Coofficients 1 2

1.000

4.566

0.945

5.194

0.878

5.630

0.819

5.666

0.773

5.417

0.831

5.018

0.865

3.215

1.028

2.396

1.162

1.861

1.375

1.277

2. 261

1.087

3.730

$1.05 \dot{6}$

4.459

1. 022

5.950

1.008

7.707

1.000

-- 
TABLE $X$

SUMMARY OF VAPOR-LIQUID EQUILIBRIUM DATA WITH SALT AS A THIRD COMPONENT

\begin{tabular}{|c|c|c|c|c|c|}
\hline System & Salt & $\begin{array}{l}\text { Compos } \\
\text { in }\end{array}$ & $\begin{array}{l}\text { sition Range } \\
\text { Mole \% }\end{array}$ & $\frac{\text { Salt }}{\text { Concentration }}$ & Authors \\
\hline Acetic Acid-Water & $\mathrm{CaCl}_{2}$ & 0 & -100 & $\begin{array}{l}10,20,30 \\
40,50 \% \text { wt. }\end{array}$ & $\begin{array}{l}\text { Garwin and } \\
\text { Hutchison (22) }\end{array}$ \\
\hline Acatic Acid-Wator & $\begin{array}{l}\text { LiCl, } \mathrm{NaCl}, \\
\mathrm{KCNS}, \mathrm{Na}_{2} \mathrm{SO}_{4} \\
\mathrm{~K}_{2} \mathrm{SO}_{4}, \mathrm{KNO}_{3} \\
\mathrm{NaC}_{2} \mathrm{H}_{3} \mathrm{O}_{2}\end{array}$ & 0.05 & $-0.4 \mathrm{~N}$ & Saturated & $\begin{array}{l}\operatorname{McBain} \text { and } \\
\operatorname{Kam}(43)\end{array}$ \\
\hline Acetic Acid-Water & $\begin{array}{l}\mathrm{NaCl}_{4}, \mathrm{Na}_{2} \mathrm{SO}_{4} \\
\mathrm{MgSO}_{4}\end{array}$ & 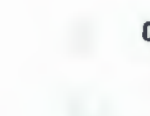 & dilute & 0-Saturatod & $\begin{array}{l}\text { Virtanen and } \\
\text { Pulki (72) }\end{array}$ \\
\hline $\begin{array}{l}\text { Acetone } \\
\text { Ethylmethyl Ketone }\end{array}$ & $\mathrm{CaCl}_{2}$ & 0 & -100 & Saturatod & Jost (33) \\
\hline Acetone-Methanol & $\mathrm{CaCl}_{2}$ & 0 & -100 & Saturated & Jost (33) \\
\hline Ethanol-Water & $\mathrm{NH}_{4} \mathrm{Cl}, \mathrm{NaCl}$ & & & & $\begin{array}{l}\text { Maizlick and } \\
\text { Tverdousky (39) }\end{array}$ \\
\hline El.hanol-Water & $\mathrm{CuCl}_{2}, \mathrm{CH}_{3} \mathrm{COOK}$ & & & & $\begin{array}{l}\text { Costa and } \\
\text { Tarraso (16) }\end{array}$ \\
\hline Ethanol-Water & $\mathrm{CuCl}_{2}$ & 0 & -100 & $\begin{array}{l}10 \& 50 \\
9 \mathrm{~m} / 100 \mathrm{~g} \text { solvent }\end{array}$ & $\begin{array}{l}\text { Tarraso }(16) \\
\text { Rouleau }(62)\end{array}$ \\
\hline Ethanol-Water & $\left(\mathrm{CH}_{3} \cdot \mathrm{C}: \mathrm{NOH}\right)_{2}$ & 0 & -100 & Saturated.. & Ciesla (15) \\
\hline
\end{tabular}


TABLE $X$ (CONTINUED)

\begin{tabular}{|c|c|c|c|c|c|}
\hline System & Salt & $\begin{array}{r}\text { Compo } \\
\text { in }\end{array}$ & $\begin{array}{l}\text { sition Range } \\
\text { Mole } \%\end{array}$ & $\begin{array}{l}\text { Salt } \\
\text { Concentration }\end{array}$ & Authors \\
\hline Ethanol-Water & $\mathrm{CaCl}_{2}, \mathrm{KCl}, \mathrm{NH}_{4} \mathrm{Cl}_{3}$ & 0 & -100 & Saturated & 75 \\
\hline Ethanol-Water & $\mathrm{CaCl}_{2}, \mathrm{NaOH}, \mathrm{Na}_{2} \mathrm{C}_{2}$, & 91 & -100 & Saturated & 42 \\
\hline Ethanol-Water & $\mathrm{Hg}_{2} \mathrm{Cl}_{2}$ & 0 & -100 & Saturated & 31 \\
\hline Ethanol-Water & $\begin{array}{l}\mathrm{HgCl}_{2}, \mathrm{ZnCl}_{2}, \mathrm{KCl}, \\
\mathrm{NaCl}, \mathrm{KOA}_{\mathrm{C}}\end{array}$ & & & & 41 \\
\hline Ethanol-Water & $\mathrm{KNO}_{3}$ & 0 & -100 & Saturated & 57 \\
\hline Ethanol-Water & $\mathrm{K}_{2} \mathrm{SO}_{4}, \mathrm{NaNO}_{3}$ & 8 & -20 & Saturated & 70 \\
\hline Ethanol-Water & $\mathrm{K}_{2} \mathrm{CO}_{3}$ & 50 & -90 & Saturated & 36 \\
\hline Ethanol-Water & $\mathrm{NaCl}$ & 0 & -100 & & $31,33,63$ \\
\hline Ethanol-Water & $\begin{array}{l}\mathrm{NaOR} \\
R=A I R_{y 1} \\
R=A I_{y 1}\end{array}$ & 89 & -98 & Saturated & 36 \\
\hline Ethylene Glycol Water & $\mathrm{Na}_{2} \mathrm{SO}_{4}, \mathrm{KCl}, \mathrm{KBI}$ & 0 & -100 & Saturated & 20 \\
\hline Ethylene Glycol Water & $\mathrm{Na}_{2} \mathrm{SO}_{4}$ & 0 & -100 & Saturated & 21 \\
\hline $\begin{array}{l}\text { Formic Acid } \\
\text { Caproic Acid }\end{array}$ & $\mathrm{LiCl}_{3} \mathrm{NaCl}$ & & & & 53 \\
\hline
\end{tabular}


TABle $X$ (CONTINUED)

\begin{tabular}{|c|c|c|c|c|c|}
\hline System & Salt & Comp & $\begin{array}{l}\text { sition Rang } \\
\text { Molo } \%\end{array}$ & $\begin{array}{c}\text { Salt } \\
\text { Concentration }\end{array}$ & Authors \\
\hline Formic Acid-Water & $\begin{array}{l}\mathrm{CaCl}_{2}, \mathrm{CaSO}_{4}, \\
\mathrm{MgCl}_{2}, \mathrm{NaCl}^{\prime} \\
\mathrm{Na}_{2} \mathrm{SO}_{4}, \mathrm{HCOOCa}, \\
\mathrm{HCOOM9}, \mathrm{HCOONa}_{4}, \\
\mathrm{HCOONH}_{4},\left(\mathrm{NH}_{4}\right)_{2} \mathrm{SO}_{4}\end{array}$ & 0 & -100 & Saturated & 26 \\
\hline Glycerol-Water & $\mathrm{NaCl}$ & 0 & -100 & Saturated & 11 \\
\hline Methanol-Toluene & $\mathrm{NaBr}$ & 0 & -100 & Saturated & This work \\
\hline Pyridine-water & $\mathrm{NaCl}$ & & & & 73 \\
\hline Phenol-Water & $\mathrm{NaCl}$ & 0 & -6 & $0-17$ wt.\% & 4 \\
\hline Deuterium Oxide Water & salts & & & & 25 \\
\hline $\begin{array}{l}\text { Water-Hydrochloric } \\
\text { Acid }\end{array}$ & Several & & & & 53 \\
\hline Water-Carboxylic Acid & Soveral & & & & 53 \\
\hline$m-x y l e n e-p-x y l$ ne & $\mathrm{SbCl}_{2}$ & & & & \\
\hline
\end{tabular}


TABLE XI

SOLUBILITIES OF VARIOUS 5 ALTS IN ALCOHOL AT ROOM TEMPERATURE in Gms/100 GI $\mathrm{m}$ SOLVENT

\begin{tabular}{cccc}
\hline \hline Solvent & $\mathrm{NaI}$ & $\mathrm{CuCl}_{2}$ & $\mathrm{Ca}\left(\mathrm{NO}_{3}\right)_{2}$ \\
\hline MEOH & 83.3 & 36.5 & 65.5 \\
ETOH & 58.8 & 35.7 & -- \\
PROH & 26.3 & 30.5 & 36.5 \\
\hline
\end{tabular}


TABLE XII

RELATIVE VOLATILITIES OF METHANOL-TOLUENE MIXTURES (Burke et al.)

\begin{tabular}{ccc}
\hline Mole Fraction methanol & $\begin{array}{c}y_{1} \\
x_{1}\end{array}$ & Relative Volatility \\
\hline 0.046 & 0.519 & 22.50 \\
0.058 & 0.627 & 28.095 \\
0.070 & 0.704 & 32.700 \\
0.094 & 0.777 & 35.15 \\
0.114 & 0.793 & 29.826 \\
0.132 & 0.801 & 26.730 \\
0.234 & 0.813 & 14.465 \\
0.330 & 0.822 & 9.482 \\
0.439 & 0.828 & 6.186 \\
0.675 & 0.842 & 2.575 \\
0.830 & 0.866 & 1.324 \\
0.870 & 0.878 & 1.027 \\
0.930 & 0.912 & 0.777 \\
0.974 & 0.957 & 0.585 \\
\hline
\end{tabular}




\section{TABLE XIII}

VAPOR PRESSURES OF METHANOL AND OF TOLUENE AT VARIOUS TEMPERATURES

\begin{tabular}{cc}
\hline Temperature, ${ }^{\circ} \mathrm{C}$. & Vapor Pressure in mm Hg \\
\hline 39.9 & 400 \\
64.7 & 760 \\
84.0 & 1520 \\
112.5 & 3800 \\
138 & 7600 \\
& \\
40.3 & TOLUENE \\
51.9 & 60 \\
69.5 & 100 \\
89.5 & 200 \\
110.6 & 400 \\
136.5 & 760 \\
& 1520 \\
\hline
\end{tabular}




\section{$X$. NOMENCLATURE}

$$
\begin{aligned}
I & =\text { current } \\
R & =\text { resistance } \\
V & =\text { voltage } \\
\text { subscript }_{1} & =\text { methanol } \\
\text { subscript }_{2} & =\text { toluene }
\end{aligned}
$$




\section{BIELIOGRAPHY}

1. Albanesi, G., I. Pasquon, and P. Genoni. Chem. $\mathbf{a}$. ind. (Milan), 39, 814 (1957).

2. Benedict, M., C.A. Johnson, E. Solomon, and L.C. Rubin. Irans. Am. Inst. Chem. Engrs., 41, 371 (1945).

3. Bittrich, H.J. Chem. Tech. (Berlin), 14, 507 (1962).

4. Bogart, M., and A, Brunjes, Chem. Eng. Progr., 44, $95(1948)$.

5. Bourne, J.R. Cham. Eng. Sci., 19, 508 (1964).

6. Bowden, W.W. Ph.D. Thesis, Purdue University, West Lafayette (1965).

7. Brown, I. and F. Smith. Australian J. Chem., 10, 423 (1957).

8. Burka, D.E., G.C. Williams, and C.A. Plank. J. Cham. Eng. Data, 9, 212 (1964).

9. Butta, H. Collection Czechoslov. Chem. Communs., 22 $1680(1957)$.

10. Chao, K.C. Ind. Eng. Chem., 51, 93 (1959).

11. Chen, D.H.T. M.S. Thesis, University of Rhode Island, Kingston (1961).

12. Chiao, T.T. M.S. Thesis, University of Rhode Island, Kingston (1957).

13. Chidbaram, S., and G. Narsimhan. Cham. Eng., 71, 135 (1964).

14. Chu, J.C. Distillation Equilibrium Data. New York: Reinholtz (1950).

15. Ciesla, E. M.S. Thesis, University of Rhode Island, Kingston (1955).

16. Costa, N.E. and J.M. Tarraso. Am. Soc. Esp. Fis. Quin., B48, 441 (1952).

17. Daniels, F., and R.A. Alberty. Physical Chemistry. Second Edition. New York: John Wiley \& Sons, 1961. 
18. Danov, S.M., and L.V. Mol'nikova. Tr. po Khim. i. Khim. Tekhnol, 2, 200 (1963).

19. Faith, W.L., D.B. Keyes, and R.L. Clark. Industrial Chemicals. Second Edition. New York: Johnwiley \& Sons, 1957.

20. Fogg, E.T. Ph.D. Thesis, University of Pennsylvania, Philadelphia (1953).

21. Fox, J.M. M.S. Thesis, University of Pennsylvania, Philadelphia (1949).

22. Garwin, L., and K.E. Hutchison. Ind. Eng. Chem., 42, 727 (1950).

23. Goe, E.A., W.K. Cunningham, and R.A. Heindl. Ind. Eng. Chem., 39, 1178 (1947).

24. Ginnings, P.M., and D. Robbins. J. Am. Chem. Soc., 52, 2282 (1930).

25. Googin, J.M., and H.A. Smith. Abstracts of Papers. Amer. Chem. Soc. Meting, Chicago, Illinois, September, 1953, p. 61R.

26. Guyer, A., Guyer, A., Jr., and B.K. Johnson. Helv. Chim. Acta, 38, 946 (1955).

27. Hala, E., J. Pick, V. Fried, and D. Vilim. Vapor-Liquid Equilibrium. Now York: Pergamon Press, 1958.

28. Herington, E.F.G. J. Inst. Petrol., 37, 457 (1951).

29. Hildebrand, J.H., and R.L. Scott. Solubility of NonEloctralytes. Third Edition. New York: Reinhold (1950).

30. Hodgman, C.D. (od.). Handbook of Chemistry and Physics. Forty-second Edition. Cleveland: The Chemical Rubber Publishing Company, 1960.

31. Johnson, A.I., and W.F. Furter. Can. J. of Cham. Engr., 38, $78(1960)$.

32. Can. J. Technol, 34, 413 (1957).

33. Josh, W. Chem. Ing. Techn., 23, 64 (1951).

34. Koulmans, A.I.m. Gas Chromatoqraphy. Second Edition. New York: Reinhold, 1959.

35. Kurmanadharao, K.V., V.V.G. Krishnamurty, and C.V. Rao. Rec. Trav. Chim., 76, 769 (1957).

36. Kyrides, L.P., T.S. Carswell, C.E. Pf iffer, and R.S. 㲘us, Ind. Éng. Chem. $24,795(1932)$. 
37. Lu, B.C.Y. Ind. Eng. Chem, 53, 871 (1960).

33. - at al. 1.Chem. Eng. Data, 8, 549 (1963).

39. maizlick, R.S., and I.P. Tverdovskij. Zh. Fiz. Khim., $\underline{27}, 1597$ (1953).

40. Malesinski, W. Bull. Acad. Polon. Sci, Ser. Sci. Sci. Chim., 2, 335 (1961).

41. Mariller, C., and J. Contant. Bull. Assoc. Chem. suer. Dist., 42, 288 (1925).

42. - Bull. Assoc. Chem. Suer. Dist., 46, 489 (1929).

43. McBain, J.W., and J. Kam. J. Chem. Soc. (London), 115 , 1332 (1919).

44. morachevskii, A.G., and V.T. Zharov. Zh. Prikl. Khim,, 37, 604 (1964).

45. Marrison, R.T., and R.N. Boyd. Organic Chemistry. Bostan: Allyn and Bacon, Inc., 1959.

46. Murti, P. S., and M. Vanwinkle. A.I.Ch.E. Journal, 3 , $517(1957)$.

47. Myers, H.S. A.I.Ch.E. Journal, 3, 467 (1957).

48. Ocon, J., and F. Rebolleda. Anales real Soc. Espain. fis y quim (Madrid), 54E, 525 (1958).

49. Othmer, D.F., R.C. Kowalski, and L.m. Naphtali. Ind, Eng. Chem., 51, 89 (1959).

50. Anal. Chem., 20, 763 (1948).

51. Perry, J.H. (od.). Chemical Engineers' Handbook. Fourth Edition. New York: Mecraw-Hill, 1963. 52. Pick, J., E. Hala, and V. Fried. Chem. listy, 52,

53. Quartardi, A. Ann. Chim. Appl. Roma, 33, 141 (1943).

54. Ramalho, R.S., and N.S. Edgett. J. Chem. Eng. Data, 舀, 324 (1964).

55. Rao, V.N.K., D.R. Swami, and N.N. Rao. J. Sci. Ind. Research (India), 16B, 294 (1957).

56. Redich, D., and A.T. Kistar. Ind. Eng. Chem., 40, $345(1948)$.

57. Rieder, R.m, and A.R. Thompson. Ind. Eng. Cham., 42, 379 (1950). 
58. Rius, A., J.L. Dtaro do las Giandara, and J.R. Alvaraz Gonzalez. Anales roal soc. espan. fis $y$ quim., 53B, 171 (1957).

59. espan. fis y quim., 56́, 629 (1960).

60. Robinson, C.S., and E.R. Gilliland. Elements of Fractional Distillation. Fourth Edition. New York: MeGraw-Hill, 1950.

61. Rock, H. Erit. Chem. Eng., 3, 20 (1953).

62. Rauleau, D.J.C. B.S. Thasis, University of attawa, ottawa (1957).

63. Samaddar, S.P., and S.K. Vandi. Irans. Indian Inst. Chem. Enors., 2, 29 (1948-49).

64. Seidell, A. Solubilities of Inorganic and Organic compounds. Second Edition. New York: Van Nostrand (1919).

65. Subbarao, a.V., and Venkatanao. Ean.J. Chem.Eng., 42, $266(1964)$.

66. Tao, L.C. Ind. Eng. Chem., 56, 36 (1964).

67. Techo, R. Chem. Eng. 5ci., 18, 27 (1963).

68. Thompson, A.R., and H.C. Molstad. Ind. Eng. Chom., 37, 1244 (1945).

69. 478 , and R.E. Vener. Ind. Eng. Chem., 40, 478

70. Tursi, R.R., and A.R. Thompson. Chem. Eng. Progr., 47, $304(1951)$.

71. Vaner, R.E. Ph.D. Thesis, University of Pennsylvania, Philadalphia (1948).

72. Virtanen, A.I., and J. Pulki. J.Am. Chem. Soc., 50, $3138(1928)$.

73. Vriens, G.N., and E.C. Medcalf. Abstracts of Papers, Divi Ind. Eng. Chem., A.C.S. Meting, Atlantic City, New Jersey, Sept., 1952.

74. Walker, W.H., W.K. Lowis, W.H. McAdams, and E.R. Gililiand. Principles of Chemical Engineering. Third Edition. New York: McGraw-Hill, 1937.

75. Yamamoto, Y., T. Miaruyamo, and K. Heri. Chem. Eng. (Japan), 16, $165(1952)$. 
76. Zieborak, K., W. Brzostowski, and J. Kaminski. BuIl. acad. polon. sci. Sar. sci., chim., geol. et geoqraph. E, 377 (1958).

77. Ser. sci., chim., qeol. et qeograph, 6 , 169 (1958). 